BNL-112693-2016-JA

\begin{abstract}
Directional Charge Transfer Mediated by Mid-Gap States: A Transient Absorption Spectroscopy Study of CdSe Quantum Dot/ $\beta-\mathrm{Pb}_{0.33} \mathrm{~V}_{2} \mathrm{O}_{5}$ Heterostructures
\end{abstract}

\author{
Christopher C. Milleville, Kate E. Pelcher, Matthew Y. Sfeir, \\ Sarbajit Banerjee, and David F. Watson
}

Submitted to the Journal of Physical Chemistry

February 2016

Center for Functional Nanomaterials

Brookhaven National Laboratory

\author{
U.S. Department of Energy \\ USDOE Office of Science (SC), \\ Basic Energy Sciences (SC-22)
}




\section{DISCLAIMER}

This report was prepared as an account of work sponsored by an agency of the United States Government. Neither the United States Government nor any agency thereof, nor any of their employees, nor any of their contractors, subcontractors, or their employees, makes any warranty, express or implied, or assumes any legal liability or responsibility for the accuracy, completeness, or any third party's use or the results of such use of any information, apparatus, product, or process disclosed, or represents that its use would not infringe privately owned rights. Reference herein to any specific commercial product, process, or service by trade name, trademark, manufacturer, or otherwise, does not necessarily constitute or imply its endorsement, recommendation, or favoring by the United States Government or any agency thereof or its contractors or subcontractors. The views and opinions of authors expressed herein do not necessarily state or reflect those of the United States Government or any agency thereof. 


\title{
Directional Charge Transfer Mediated by Mid-Gap States: A Transient Absorption Spectroscopy Study of CdSe Quantum $\mathrm{Dot} / \boldsymbol{\beta}-\mathrm{Pb}_{0.33} \mathrm{~V}_{\mathbf{2}} \mathrm{O}_{5}$ Heterostructures
}

\author{
Christopher C. Milleville, ${ }^{\text {ๆ1 }}$ Kate E. Pelcher, ${ }^{\text {ๆ2 }}$ Matthew Y. Sfeir, ${ }^{3}$ Sarbajit Banerjee, ${ }^{2 *}$ and David \\ F. Watson ${ }^{1 *}$ \\ ${ }^{1}$ Department of Chemistry, University at Buffalo, The State University of New York, Buffalo, NY 14260-3000 (USA); \\ dwatson3@buffalo.edu \\ ${ }^{2}$ Department of Chemistry and Department of Materials Science and Engineering, Texas A\&M University, College \\ Station, TX 77842-3012 (USA); banerjee@chem.tamu.edu \\ ${ }^{3}$ Center for Functional Nanomaterials, Brookhaven National Laboratory, Upton, NY 11973-5000 (USA) \\ "These authors contributed equally to this work
}

\begin{abstract}
For solar energy conversion, not only must a semiconductor absorb incident solar radiation efficiently but also its photoexcited electron-hole pairs must further be separated and transported across interfaces. Charge transfer across interfaces requires consideration of both thermodynamic driving forces as well as the competing kinetics of multiple possible transfer, cooling, and recombination pathways. In this work, we demonstrate a novel strategy for extracting holes from photoexcited CdSe quantum dots (QDs) based on interfacing with $\beta-\mathrm{Pb}_{0.33} \mathrm{~V}_{2} \mathrm{O}_{5}$ nanowires that have strategically positioned mid-gap states derived from the intercalating $\mathrm{Pb}^{2+}$-ions. Unlike mid-gap states derived from defects or dopants, the states utilized here are derived from the intrinsic crystal structure and are thus homogeneously distributed across the material. $\mathrm{CdSe} / \beta-\mathrm{Pb}_{0.33} \mathrm{~V}_{2} \mathrm{O}_{5}$ heterostructures were assembled using two distinct methods: successive ionic layer adsorption and reaction (SILAR) and linker-assisted assembly (LAA). Transient absorption spectroscopy measurements indicate that electrons and holes can be transferred from the photoexcited CdSe QDs to the conduction and mid-gap states, respectively, of $\beta-\mathrm{Pb}_{0.33} \mathrm{~V}_{2} \mathrm{O}_{5}$ nanowires for both types of heterostructures. Holes were transferred on time scales less than 1 ps, whereas electrons were transferred more slowly on time scales of approximately 2 ps. In contrast, for analogous heterostructures consisting of CdSe QDs interfaced with $\mathrm{V}_{2} \mathrm{O}_{5}$ nanowires (wherein mid-gap states are absent), only electron transfer was observed. Interestingly, electron transfer was readily achieved for CdSe QDs interfaced with $\mathrm{V}_{2} \mathrm{O}_{5}$ nanowires by the SILAR method; however, for interfaces incorporating molecular linkers, electron transfer was observed only upon excitation at energies substantially greater than the band-gap absorption threshold of CdSe. Transient absorbance decay traces reveal longer exciton lifetimes (1-3 $\mu \mathrm{s}$ ) for $\mathrm{CdSe} / \mathrm{\beta}-\mathrm{Pb}_{0.33} \mathrm{~V}_{2} \mathrm{O}_{5}$ heterostructures relative to bare $\beta-\mathrm{Pb}_{0.33} \mathrm{~V}_{2} \mathrm{O}_{5}$ nanowires $(0.2-0.6 \mu \mathrm{s})$; the difference is attributed to surface passivation of intrinsic surface defects in $\beta-\mathrm{Pb}_{0.33} \mathrm{~V}_{2} \mathrm{O}_{5}$ upon interfacing with $\mathrm{CdSe}$ (290 words).
\end{abstract}




\section{Introduction}

Harvesting sunlight and storing the energy of the absorbed photons in chemical bonds (in the form of

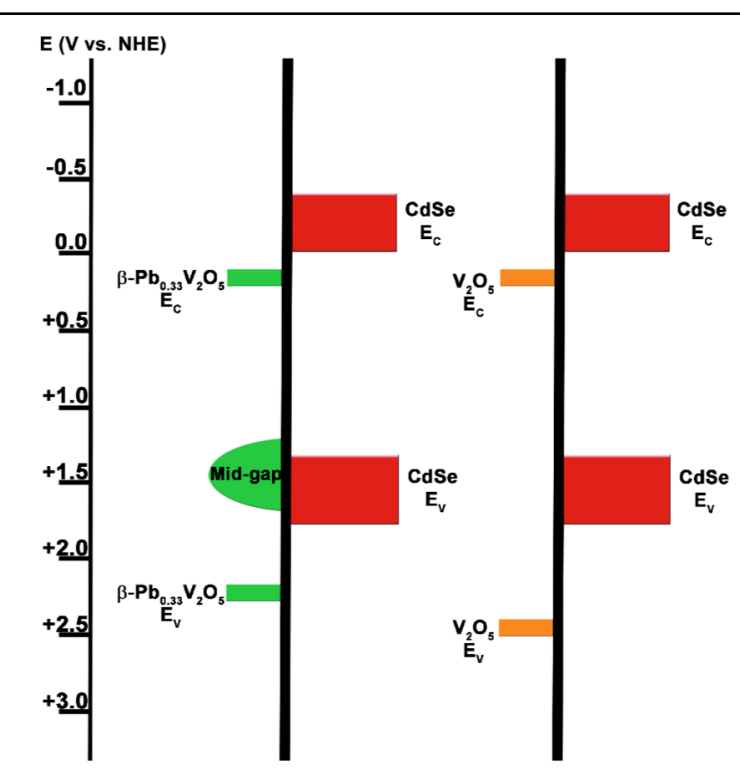

Figure 1. Energy diagram depicting approximate relative energy positioning of valence and conduction band edges of $\mathrm{CdSe}, \beta-\mathrm{Pb}_{0.33} \mathrm{~V}_{2} \mathrm{O}_{5}$, and $\mathrm{V}_{2} \mathrm{O}_{5}$, as determined from $\mathrm{X}$-ray photoemission spectroscopy. The mid-gap state of $\beta-\mathrm{Pb}_{0.33} \mathrm{~V}_{2} \mathrm{O}_{5}$ overlaps with the valence-band-edge of CdSe. solar fuels) or by doing electrical work (as in photovoltaic devices) is critical to reducing our reliance on fossil fuels. ${ }^{1-5}$ For effective solar energy conversion, a semiconductor must not only absorb a large portion of the incident solar radiation but the photoexcited electron-hole pairs must further be separated and transported across interfaces..$^{2-3,6-7}$ The kinetics of charge separation and transport are a critical consideration to mitigate the recombination or cooling of photogenerated charges. ${ }^{8-10}$ Achieving efficient charge transfer and separation across semiconductor interfaces is thus predicated on careful alignment of thermodynamic driving forces (which in turn depends on relative band alignments) and on the competing kinetics of directional charge transfer, cooling, and recombination pathways. The appropriate alignment of bands is a first and necessary criterion for achieving charge transfer. $^{3,}$ 7, 11 In many cases, a visible-light absorbing semiconductor is paired with a wide band gap semiconductor, and charge carriers are injected into the latter upon photoexcitation of the former. ${ }^{1,3,5,12-13}$ Simple binary semiconductors that have traditionally been studied for photovoltaics have clearly defined valence and conduction band (CB) edges separated by a bandgap and are difficult to reconfigure thereby establishing some immutable limitations on tunability of the thermodynamic driving force. A promising alternative is to strategically position electronic states in a semiconductor through the introduction of dopants or defect states. ${ }^{14-15}$ Mid-gap states are often defined by defects or surface traps. ${ }^{10,16-18}$ In contrast, we have recently designed $\mathrm{M}_{x} \mathrm{~V}_{2} \mathrm{O}_{5}$ bronzes wherein the mid-gap states derive from stereoactive lone-pairs of posttransition-metal cations and are thus homogenously distributed across the crystal. ${ }^{19}$ Here, we demonstrate that an intercalation-induced mid-gap state in $\beta-\mathrm{Pb}_{0.33} \mathrm{~V}_{2} \mathrm{O}_{5}$ can mediate directional charge transfer of both electrons and holes from photoexcited CdSe quantum dots (QDs) to the $C B$ and midgap-states of $\beta-\mathrm{Pb}_{0.33} \mathrm{~V}_{2} \mathrm{O}_{5}$, respectively. The charge transfer dynamics are contrasted to those of $\mathrm{CdSe}$ QDs interfaced with $\mathrm{V}_{2} \mathrm{O}_{5}$.

Several promising alternatives to traditional schemes of photoexcitation and charge separation within a semiconductor have been explored to increase the amount of solar energy absorbed and the efficiency with which it is converted to other energy forms. ${ }^{2}$ Tandem solar cells, multi-junction cells, multiple 
exciton generation, intermediate band solar cells, and hot-carrier solar cells are examples of different methods that demonstrate promise. ${ }^{1-4,6,20-23}$ Metal oxides have a long history of being used for a variety of applications due to their semiconducting nature. However, the very positive valence band (VB) edge potentials of a majority of metal oxide semiconductors limit their practical use in applications for harvesting solar energy. In previous work, we have found that ternary vanadium oxide bronzes (with the formula of $\beta-M_{x} V_{2} O_{5}$, where $M$ is a post-transition-metal with a stereoactive lone pair and $x$ is its stoichiometry) were found to possess mid-gap states slightly positive of the oxidation potential of water. ${ }^{15}$ This mid-gap state is not present in $\mathrm{V}_{2} \mathrm{O}_{5}$, the parent oxide of the vanadium oxide bronze. ${ }^{24}$ Initial density functional theory calculations predicting the presence of a mid-gap state have recently been experimentally verified using high-energy $X$-ray photoemission spectroscopy. ${ }^{14-15,}{ }^{18}$ The energy positioning of the mid-gap state can be varied by choice of the intercalating cation, thereby providing a facile means for tuning the alignment of these levels with respect to other materials. ${ }^{18-19}$ The approximate relative energy positioning of this mid-gap state, along with the VB edge potential $\left(E_{V}\right)$ and $\mathrm{CB}$ edge potential $\left(E_{C}\right)$ of both $\beta-\mathrm{Pb}_{0.33} \mathrm{~V}_{2} \mathrm{O}_{5}$ and $\mathrm{V}_{2} \mathrm{O}_{5}$ as well as $\mathrm{CdSe}$ are shown in Figure 1 . This scheme suggests that upon photoexcitation of the CdSe $Q D$ (resulting in creation of a hole in the VB), hole transfer from the $\mathrm{VB}$ of the CdSe $\mathrm{QD}$ to the mid-gap state of $\beta-\mathrm{Pb}_{0.33} \mathrm{~V}_{2} \mathrm{O}_{5}$ is thermodynamically favorable, providing a driving force to extract the hole and ultimately to propagate it along the nanowire for solar fuel production. Indeed, in previous work, we have demonstrated the successful synthesis of $\mathrm{CdSe} / \beta-\mathrm{Pb}_{0.33} \mathrm{~V}_{2} \mathrm{O}_{5}$ heterostructures and experimentally verified substantial overlap of the $\mathrm{CdSe} \mathrm{VB}$ edges with the mid-gap states of $\beta-\mathrm{Pb}_{0.33} \mathrm{~V}_{2} \mathrm{O}_{5}$ using high-energy $\mathrm{X}$-ray photoemission spectroscopy. ${ }^{14}$ Such a heterostructure represents a readily reconfigurable platform wherein the VB edges of the QD can be modulated by compositional variation and size, whereas the energy positioning of the mid-gap state can be tuned by choice of the intercalating cation, thereby providing access to several routes for tuning the thermodynamic driving forces for charge transfer.

However, thermodynamic alignment of energy levels is but one part of the equation. As noted above, directional charge transfer needs to compete with back-electron transfer, charge recombination, and cooling pathways. Several studies have shown that the nature of the interface strongly affects the kinetics of charge transfer. ${ }^{25-30}$ Here, we seek to explore the kinetics of charge transfer in $\mathrm{CdSe} / \beta$ $\mathrm{Pb}_{0.33} \mathrm{~V}_{2} \mathrm{O}_{5}$ heterostructures using transient absorption spectroscopy as a function of the nature of the interface. Charge transfer dynamics are contrasted for heterostructures prepared via two distinct routes: linker-assisted assembly (LAA) and successive ionic layer adsorption and reaction (SILAR). LAA allows for more precise control over QD size and the separation between the two components, whereas SILAR facilitates direct contact between the QDs and the nanowires but does not allow for precise size control. The charge transfer kinetics for $\mathrm{CdSe} / 6-\mathrm{Pb}_{0.33} \mathrm{~V}_{2} \mathrm{O}_{5}$ heterostructures are contrasted to those of $\mathrm{CdSe} / \mathrm{V}_{2} \mathrm{O}_{5}$ heterostructures to elucidate the role of the mid-gap states in facilitating charge transfer.

\section{Experimental Section}

\section{Synthesis of $\beta-\mathrm{Pb}_{0.33} \mathrm{~V}_{2} \mathrm{O}_{5}$ and $\mathrm{V}_{2} \mathrm{O}_{5}$ Nanowires}

$\beta-\mathrm{Pb}_{0.33} \mathrm{~V}_{2} \mathrm{O}_{5}$ nanowires were prepared using a one-step hydrothermal reaction as reported previously. ${ }^{15}$ Briefly, stoichiometric amounts of $\mathrm{Pb}\left(\mathrm{CH}_{3} \mathrm{COO}\right)_{2} \cdot 3 \mathrm{H}_{2} \mathrm{O}$ and $\mathrm{V}_{2} \mathrm{O}_{5}$ were placed in a 
polytetrafluoroethylene-lined acid digestion vessel (Parr) along with $16 \mathrm{~mL}$ of deionized (DI) water. The vessel was sealed in an autoclave and heated to $250^{\circ} \mathrm{C}$ for $72 \mathrm{~h}$. The product was isolated by vacuum filtration, washed with copious amounts of water, and allowed to dry in air. The resulting nanowires were ca. $170 \mathrm{~nm}$ in diameter and spanned microns in length. ${ }^{15} \mathrm{~V}_{2} \mathrm{O}_{5}$ nanowires were prepared by the oxidation of hydrothermally grown $\mathrm{V}_{3} \mathrm{O}_{7} \cdot \mathrm{xH}_{2} \mathrm{O}$ nanowires as reported in previous work. ${ }^{31}$ The $\mathrm{V}_{2} \mathrm{O}_{5}$ nanowires were ca. $150-250 \mathrm{~nm}$ in diameter and spanned hundreds of microns in length. ${ }^{31}$

\section{Synthesis of CdSe QDs}

Cysteine-capped CdSe (Cys-CdSe) QDs were synthesized as reported previously. ${ }^{32}$ Briefly, the selenium precursor was prepared by refluxing an aqueous solution of Se powder and $\mathrm{Na}_{2} \mathrm{SO}_{3}$ overnight, and the cadmium precursor was an aqueous solution of $3 \mathrm{CdSO}_{4} \cdot 8 \mathrm{H}_{2} \mathrm{O}$ and cysteine. The $\mathrm{pH}$ of the cadmium precursor was titrated to 12.5-13.0 with solid $\mathrm{NaOH}$. The hot selenium precursor was added to the cadmium precursor and allowed to stir for $30 \mathrm{~min}$. The resulting dispersions of Cys-CdSe QDs, hereafter referred to as Cys-CdSe(sm) QDs, were purified by solvent-non-solvent $\left(\mathrm{H}_{2} \mathrm{O}: \mathrm{MeOH}, 3: 1\right)$ washing to remove excess reagents. Larger Cys-CdSe (Cys-CdSe(Ig)) QDs were synthesized and purified by the same procedure except that the cadmium precursor was heated to, and maintained at, $80^{\circ} \mathrm{C}$ for the duration of the reaction $(2 \mathrm{~h})$.

\section{Functionalization of $\beta-\mathrm{Pb}_{0.33} \mathrm{~V}_{2} \mathrm{O}_{5}$ and $\mathrm{V}_{2} \mathrm{O}_{5}$ Nanowires with CdSe QDs by SILAR and LAA}

CdSe was deposited onto $\beta-\mathrm{Pb}_{0.33} \mathrm{~V}_{2} \mathrm{O}_{5}$ nanowires via SILAR and LAA following our reported methods. ${ }^{14}$ In a single SILAR cycle, CdSe QDs were grown directly onto $\beta-\mathrm{Pb}_{0.33} \mathrm{~V}_{2} \mathrm{O}_{5}$ nanowires by sequentially mixing the nanowires with a $50 \mathrm{mM}$ solution of $\mathrm{Cd}\left(\mathrm{NO}_{3}\right)_{2}$ in ethanol followed by a $50 \mathrm{mM}$ solution of $\mathrm{Na}_{2} \mathrm{Se}$ in ethanol. The nanowires were washed with ethanol following each mixing step in order to remove excess ions. This SILAR process was performed once (1x SILAR samples), three times (3x SILAR samples), or five times ( $5 x$ SILAR samples) to vary the density of CdSe QDs on the surface of the nanowires. An analogous procedure was utilized to coat $\mathrm{V}_{2} \mathrm{O}_{5}$ nanowires with $\mathrm{CdSe}$.

LAA was employed to prepare Cys-CdSe(sm)/ $\beta-\mathrm{Pb}_{0.33} \mathrm{~V}_{2} \mathrm{O}_{5}$ and $\mathrm{Cys}-\mathrm{CdSe}(\mathrm{Ig}) / \beta-\mathrm{Pb}_{0.33} \mathrm{~V}_{2} \mathrm{O}_{5}$ heterostructures (and corresponding $\mathrm{V}_{2} \mathrm{O}_{5}$ heterostructures) in which cysteine acted as a bifunctional linker molecule. As reported in our previous work, cysteine bound preferentially to CdSe via the thiolate functional group and to $\beta-\mathrm{Pb}_{0.33} \mathrm{~V}_{2} \mathrm{O}_{5}$ through an electrostatic interaction between a positively charged, protonated amine group on cysteine and the negatively charged, hydroxylated surface of $\beta-\mathrm{Pb}_{0.33} \mathrm{~V}_{2} \mathrm{O}_{5}$ (or $\mathrm{V}_{2} \mathrm{O}_{5}$ ). ${ }^{14}$ In $L A A$, an aqueous dispersion of $\beta-\mathrm{Pb}_{0.33} \mathrm{~V}_{2} \mathrm{O}_{5}$ (or $\mathrm{V}_{2} \mathrm{O}_{5}$ ) nanowires was added to an aqueous dispersion of purified Cys-CdSe(sm) or Cys-CdSe(lg) QDs and allowed to equilibrate overnight $(12-16 \mathrm{~h})$. CdSefunctionalized nanowires were recovered by centrifugation, rinsed with DI water to remove excess QDs, and subsequently dried at room temperature before characterization.

\section{Preparation of Thin Films and Diffuse Reflectance Measurements}

The nanowires and $Q D /$ nanowire heterostructures were immobilized onto glass microscope slides for diffuse reflectance and transient absorption measurements. Dispersions $(20 \mathrm{~mL})$ of $\beta-\mathrm{Pb}_{0.33} \mathrm{~V}_{2} \mathrm{O}_{5}, \mathrm{~V}_{2} \mathrm{O}_{5}$, $\mathrm{CdSe} / \beta-\mathrm{Pb}_{0.33} \mathrm{~V}_{2} \mathrm{O}_{5}$, or $\mathrm{CdSe} / \mathrm{V}_{2} \mathrm{O}_{5}$ in ethanol $(1 \mathrm{mg} / \mathrm{mL})$ were spray coated onto the substrate, forming 
semi-transparent thin films. UV-Vis diffuse reflectance spectra of sample films were obtained with an Agilent 8453 diode array spectrophotometer equipped with a Labsphere RSA-HP-53 (Hewlett-Packard) reflectance accessory.

\section{Spectroelectrochemistry Experiments}

Spectroelectrochemical measurements were performed on $\beta-\mathrm{Pb}_{0.33} \mathrm{~V}_{2} \mathrm{O}_{5}$ and $\mathrm{V}_{2} \mathrm{O}_{5}$ films to monitor changes in the absorption spectra upon oxidation or reduction. Films were prepared by spray coating nanowires onto fluorine-doped tin oxide (FTO)-coated glass slides. A one-compartment, three-electrode electrochemical cell configuration was used consisting of a thin film working electrode, a Pt mesh auxiliary electrode, and a saturated calomel (SCE) reference electrode. Electrochemical measurements were performed using a Princeton Applied Research (PAR) VersaSTAT 3 potentiostat. A quartz cuvette (1 $\mathrm{cm}$ path length) with a 24/40 ground glass joint connection was used as the cell, and the electrolyte consisted of $0.1 \mathrm{M}$ tetrabutylammonium perchlorate (Alfa Aesar, electrochemical grade) in anhydrous acetonitrile (EMD). In order to avoid contamination with water the electrolyte solution was prepared in a glovebox and then brought out immediately before beginning the experiments. The cell was further purged with nitrogen to remove dissolved oxygen. The entire cell assembly was housed on the sample stage of spectrophotometer so that absorption spectra could be obtained while performing electrochemical measurements. For $\beta-\mathrm{Pb}_{0.33} \mathrm{~V}_{2} \mathrm{O}_{5}$ films, either an oxidizing potential of $+1.75 \mathrm{~V}$ (vs. SCE) or a reducing potential of $-1.0 \mathrm{~V}$ (vs. SCE) was applied. In contrast, for $\mathrm{V}_{2} \mathrm{O}_{5}$ films, either an oxidizing potential of $+1.5 \vee$ ( $v s$. SCE) or a reducing potential of $-0.25 \mathrm{~V}$ (vs. SCE) was applied. Absorption spectra of the oxidized or reduced films were obtained after applying a potential for $5 \mathrm{~min}$. Separate films were used for the oxidation and reduction reactions in case any redox processes were irreversible. Ground state differential absorption spectra were computed by subtracting the absorption spectrum of the neutral sample from the absorption spectrum of the oxidized or reduced sample.

\section{Transient Absorption Experiments}

Transient absorption experiments were performed at the Advanced Optical Spectroscopy and Microscopy Facility in the Center for Functional Nanomaterials at Brookhaven National Laboratory (BNL). Ultra-fast transient absorption measurements were conducted using a commercial Ti:Sapphire amplified laser system (SpectraPhysics Spitfire Pro, $1 \mathrm{kHz}$ repetition rate). Excitation light was generated using a commercial optical parametric amplifier (LightConversion). Supercontinuum probe light was generated by focusing the $800 \mathrm{~nm}$ fundamental into a sapphire disc. The probe light was split into signal and reference beams, both of which were detected on a shot-by-shot basis with fiber-coupled silicon (visible) or InGaAs (infrared) diode arrays. The pump-probe delay was controlled by means of a mechanical delay stage (Newport). Nanosecond transient absorption measurements were conducted using the same ultrafast pump pulses along with an electronically delayed supercontinuum light source with a sub-ns pulse duration (EOS, Ultrafast Systems). Transient absorption spectra were collected at pump wavelengths ( $\lambda_{\text {pump }}$ ) of $360 \mathrm{~nm}, 425 \mathrm{~nm}, 490 \mathrm{~nm}$, and $600 \mathrm{~nm}$. Transient absorbance (TA) spectra presented in this manuscript were extracted from the data matrix by averaging $\Delta A$ values between 1.5 and $10 \mathrm{~ns}$ at each $\lambda_{\text {pump. }}$. TA decay traces presented in this manuscript were extracted from the data matrix by averaging $\Delta A$ values over a given range of $\lambda_{\text {probe }}$ at each delay time. 


\section{Results and Discussion}

\section{Ground-state Absorption Spectra of Unfunctionalized $\beta-\mathrm{Pb}_{0.33} \mathrm{~V}_{2} \mathrm{O}_{5}$ and $\mathrm{V}_{2} \mathrm{O}_{5}$ Nanowires}

Diffuse reflectance spectra of $\mathrm{V}_{2} \mathrm{O}_{5}$ and $\mathrm{\beta}-\mathrm{Pb}_{0.33} \mathrm{~V}_{2} \mathrm{O}_{5}$ films on glass slides are shown in Figure $2 \mathrm{~A} . \mathrm{V}_{2} \mathrm{O}_{5}$ displays an absorption onset at $580 \mathrm{~nm}$ with a steep rise in absorbance corresponding to bandgap excitation. $\beta-\mathrm{Pb}_{0.33} \mathrm{~V}_{2} \mathrm{O}_{5}$ displays an absorption onset at $615 \mathrm{~nm}$ with a gradual increase in absorbance to approximately $540 \mathrm{~nm}$, followed by a steep increase in absorbance, similar to $\mathrm{V}_{2} \mathrm{O}_{5}$. The red-shifted absorption onset for $\beta-\mathrm{Pb}_{0.33} \mathrm{~V}_{2} \mathrm{O}_{5}$ is assigned to the lower energy transition associated with excitation of an electron from the mid-gap state to $C B$ states. A gradual increase in absorbance can be attributed to a convolution of mid-gap excitation and bandgap excitation. A broad absorption feature for the mid-gap excitation is not surprising owing to a broad energy range of the mid-gap states as opposed to a single discrete energy level. Based on previous high-energy X-ray photoemission studies and density functional theory calculations, the mid-gap state represents a filled anti-bonding state derived from the hybridization of $\mathrm{Pb} 6 \mathrm{~s}$ and $\mathrm{O} 2 \mathrm{p}$ bands. ${ }^{18}$

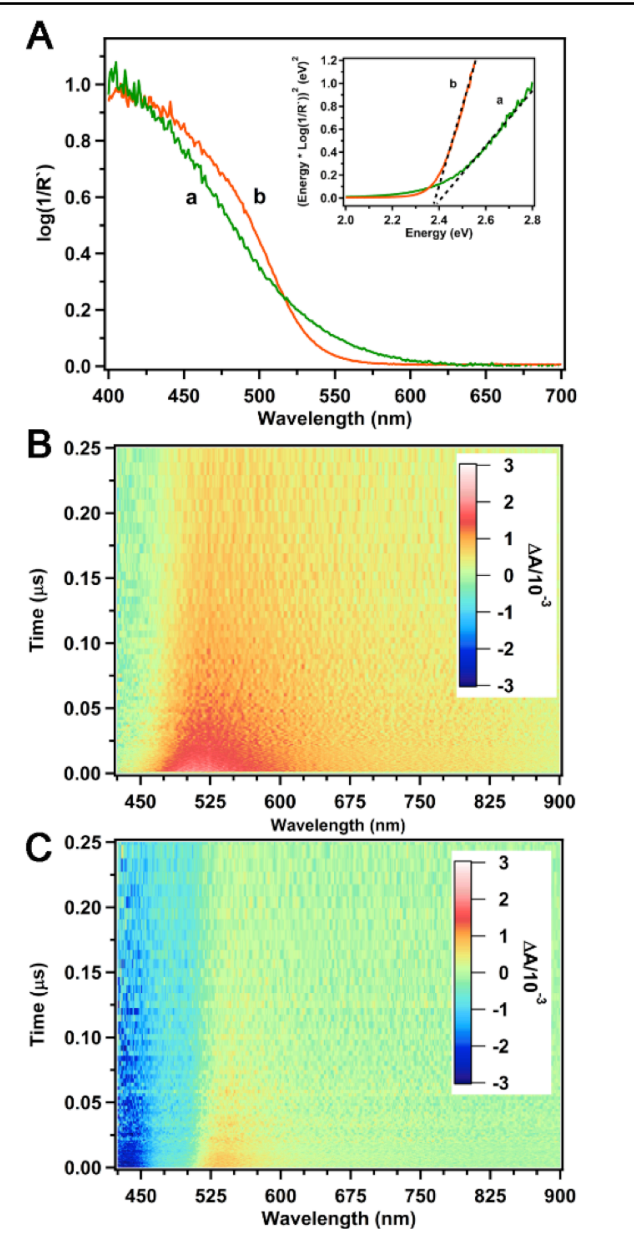

Figure 2. (A) Ground-state diffuse reflectance spectra of (a) $\beta-\mathrm{Pb}_{0.33} \mathrm{~V}_{2} \mathrm{O}_{5}$ (green) and (b) $\mathrm{V}_{2} \mathrm{O}_{5}$ (red), inset: Tauc plots; and "color maps" showing $\Delta \mathrm{A}$ at all delay times and probe wavelengths for $\beta$ $\mathrm{Pb}_{0.33} \mathrm{~V}_{2} \mathrm{O}_{5}$ (B) and $\mathrm{V}_{2} \mathrm{O}_{5}$ (C) with $\lambda_{\text {pump }}=$ $360 \mathrm{~nm}$.
Tauc plots are commonly employed to determine the optical bandgap of semiconductors by extrapolating the linear region to the abscissa. ${ }^{33-34}$ Tauc plots of (energy $\left.\times \log (1 / R)\right)^{2}$ vs. energy, where $R$ is reflectance, for $\mathrm{V}_{2} \mathrm{O}_{5}$ and $\beta-\mathrm{Pb}_{0.33} \mathrm{~V}_{2} \mathrm{O}_{5}$ (insert, Figure $2 \mathrm{~A}$ ) accentuate the mid-gap excitation features. Both plots contain a linear region, associated with bandgap excitation, and a pronounced deviation from linearity at lower energies due to intrinsic localized absorptions derived from mid-gap states. An optical bandgap of ca. $2.4 \mathrm{eV}$ was determined for both $\mathrm{V}_{2} \mathrm{O}_{5}$ and $\beta$ $\mathrm{Pb}_{0.33} \mathrm{~V}_{2} \mathrm{O}_{5}$. Closer examination of the non-linear region provides clear evidence of transitions involving the excitation of electrons from surface-localized and/or intercalative mid-gap states to the $\mathrm{CB}$. The energy difference between the absorption onset and bandgap excitation can be interpreted as the difference between the highest-energy localized mid-gap states and the VB edge. Measured differences of 0.12 and $0.37 \mathrm{eV}$ were obtained for $\mathrm{V}_{2} \mathrm{O}_{5}$ and $\beta-\mathrm{Pb}_{0.33} \mathrm{~V}_{2} \mathrm{O}_{5}$, respectively. Assuming no significant change in the distribution of localized surface states for $\beta-\mathrm{Pb}_{0.33} \mathrm{~V}_{2} \mathrm{O}_{5}$ relative to $\mathrm{V}_{2} \mathrm{O}_{5}$, the larger shift of the absorption onset relative to the band-gap excitation for $\beta-\mathrm{Pb}_{0.33} \mathrm{~V}_{2} \mathrm{O}_{5}$ can be attributed to the presence of intercalative mid-gap states at even higher energies above the VB edge than surfacelocalized states. 
Transient Absorption Spectra and Dynamics of Unfunctionalized $\beta-\mathrm{Pb}_{0.33} \mathrm{~V}_{2} \mathrm{O}_{5}$ and $\mathrm{V}_{2} \mathrm{O}_{5}$ Nanowires

Transient absorption spectra were acquired to examine excited-state spectral features and exciton dynamics of $\beta-\mathrm{Pb}_{0.33} \mathrm{~V}_{2} \mathrm{O}_{5}$ and $\mathrm{V}_{2} \mathrm{O}_{5}$ nanowires. Films of $\beta-\mathrm{Pb}_{0.33} \mathrm{~V}_{2} \mathrm{O}_{5}$ and $\mathrm{V}_{2} \mathrm{O}_{5}$ were excited at $360 \mathrm{~nm}$ and probed from $425 \mathrm{~nm}$ to $900 \mathrm{~nm}$. The excitation wavelength corresponds to an energy greater than the bandgap of both materials. Three-dimensional TA "color maps" of $\beta-\mathrm{Pb}_{0.33} \mathrm{~V}_{2} \mathrm{O}_{5}$ and $\mathrm{V}_{2} \mathrm{O}_{5}$ (Fig. $2 \mathrm{~B}$ and $2 \mathrm{C}$ ) reveal clear differences between the two samples, owing to the presence of mid-gap states in $\beta$ $\mathrm{Pb}_{0.33} \mathrm{~V}_{2} \mathrm{O}_{5}$. TA spectra ( $\Delta \mathrm{A}$ vs. wavelength) were extracted from the data matrix by averaging $\Delta \mathrm{A}$ values between $1.5 \mathrm{~ns}$ and $10 \mathrm{~ns}$ at all probe wavelengths. The TA spectrum of $\beta-\mathrm{Pb}_{0.33} \mathrm{~V}_{2} \mathrm{O}_{5}$ (Fig. $3 \mathrm{~A}$ ) is characterized by two excited state absorption bands: a more intense band centered at ca. $510 \mathrm{~nm}$ and a less-intense and broad shoulder stretching from ca. $650 \mathrm{~nm}$ into the near IR, with a center at ca. $750 \mathrm{~nm}$. The TA spectrum of $\mathrm{V}_{2} \mathrm{O}_{5}$ differs markedly, and is instead characterized by an intense bleach centered at ca. $430 \mathrm{~nm}$ and an absorption band centered at ca. $535 \mathrm{~nm}$.
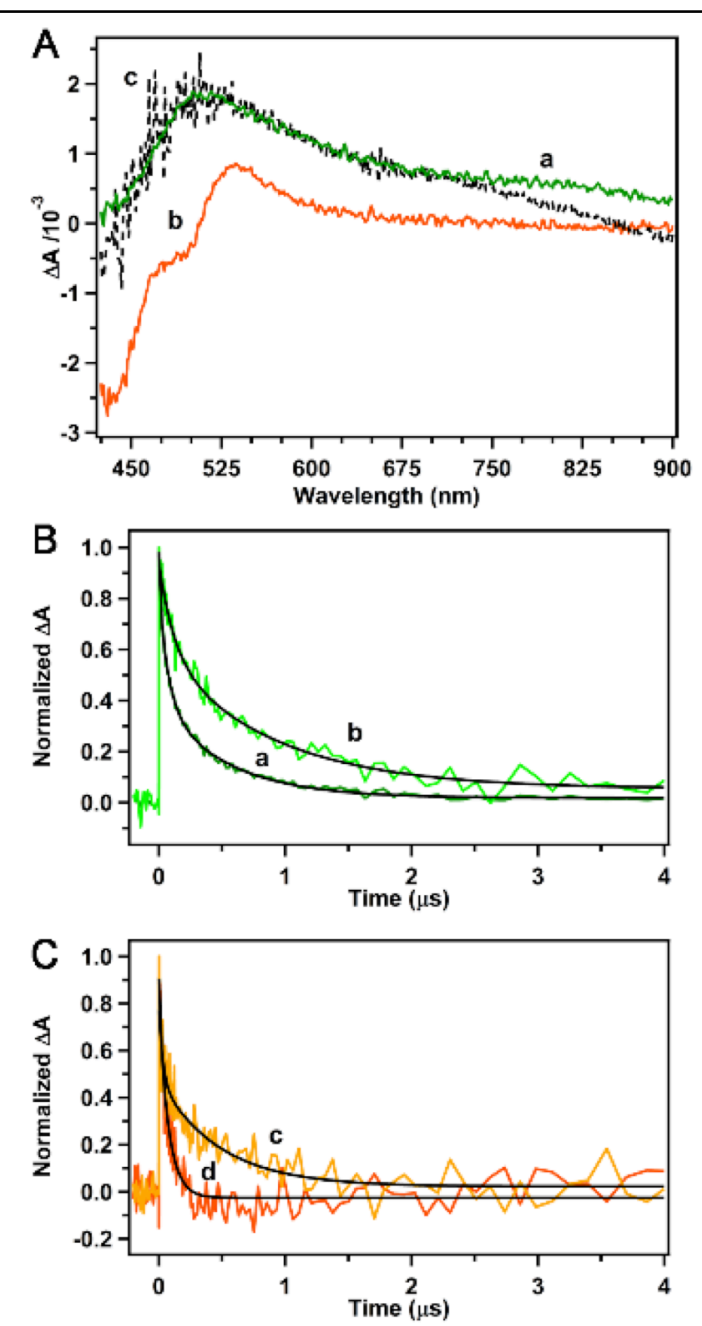

Figure 3. (A) TA spectrum of $\beta-\mathrm{Pb}_{0.33} \mathrm{~V}_{2} \mathrm{O}_{5}$ (a, green), TA spectrum of $\mathrm{V}_{2} \mathrm{O}_{5}$ (b, orange), and fit of spectrum (a) to a linear combination of oxidized and reduced $\beta-\mathrm{Pb}_{0.33} \mathrm{~V}_{2} \mathrm{O}_{5}$ (c, black) as derived from spectroelectrochemical measurements. $(B, C)$ TA decay traces and fits for $\beta-\mathrm{Pb}_{0.33} \mathrm{~V}_{2} \mathrm{O}_{5}$ at $\lambda_{\text {probe }}=510$ $\mathrm{nm}(\mathrm{a})$ and $750 \mathrm{~nm}$ (b) and for $\mathrm{V}_{2} \mathrm{O}_{5}$ at $\lambda_{\text {probe }}=430$ $\mathrm{nm}$ (c) and $535 \mathrm{~nm}$ (d). For all data, $\lambda_{\text {pump }}=360 \mathrm{~nm}$.
Spectroelectrochemical measurements were acquired to assist with the assignment of TA spectra. Ground-state absorption spectra of $\mathrm{V}_{2} \mathrm{O}_{5}$ and $\beta-\mathrm{Pb}_{0.33} \mathrm{~V}_{2} \mathrm{O}_{5}$ films on FTO electrodes were acquired under the application of either an oxidizing or reducing potential. Absorbance difference spectra were generated by subtracting the absorbance spectrum of the neutral species from that of the oxidized or reduced species (Fig. S1 in Supporting Information). Oxidation of both $\mathrm{V}_{2} \mathrm{O}_{5}$ and $\beta-\mathrm{Pb}_{0.33} \mathrm{~V}_{2} \mathrm{O}_{5}$ yielded a broad induced absorption band extending from $<375 \mathrm{~nm}$ to ca. $675 \mathrm{~nm}$. The oxidation of $\beta-\mathrm{Pb}_{0.33} \mathrm{~V}_{2} \mathrm{O}_{5}$ corresponds to the removal of electrons from filled mid-gap states that lie above the $\mathrm{VB}^{15}{ }^{18}$; thus, we assign the induced absorption to the excitation of $V B$ electrons into empty mid-gap states. For $\mathrm{V}_{2} \mathrm{O}_{5}$, which has no intercalative mid-gap states, oxidation corresponds primarily to the removal of electrons from VB states. Therefore, the induced absorbance arises from the excitation of deep-VB electrons to the VB edge. Notably, the VB of $\beta$ $\mathrm{Pb}_{0.33} \mathrm{~V}_{2} \mathrm{O}_{5}$ is characterized by a pronounced $\mathrm{Pb}$ $6 s-02 p$ bonding state that does not exist for $\mathrm{V}_{2} \mathrm{O}_{5} \cdot{ }^{18}$ Reduction of both $\mathrm{V}_{2} \mathrm{O}_{5}$ and $\beta-\mathrm{Pb}_{0.33} \mathrm{~V}_{2} \mathrm{O}_{5}$ yielded a bleach of the band-gap absorption (Fig. S1), consistent with the Burstein-Moss effect. ${ }^{35-37}$ Reduction involves the filling of $\mathrm{CB}$ states, 
effectively increasing the optical bandgap and blue-shifting the band-gap absorption onset. Reduced $\beta$ $\mathrm{Pb}_{0.33} \mathrm{~V}_{2} \mathrm{O}_{5}$ also exhibited an induced absorption band extending from ca. $620 \mathrm{~nm}$ into the near IR. We assign this absorption to the excitation of electrons in the $C B$ of reduced $\beta-\mathrm{Pb}_{0.33} \mathrm{~V}_{2} \mathrm{O}_{5}$ to higher-energy states, consistent with established spectral assignments for reduced metal oxides. ${ }^{36-39}$

The spectroelectrochemical data were used to assign features in the TA spectra of $\beta-\mathrm{Pb}_{0.33} \mathrm{~V}_{2} \mathrm{O}_{5}$ and $\mathrm{V}_{2} \mathrm{O}_{5}$. We assign the $510 \mathrm{~nm}$ absorption band in the TA spectrum of $\beta-\mathrm{Pb}_{0.33} \mathrm{~V}_{2} \mathrm{O}_{5}$, which exhibits similar absorption maximum and spectral profile as the induced absorption band of oxidized $\beta-\mathrm{Pb}_{0.33} \mathrm{~V}_{2} \mathrm{O}_{5}$, to the excitation of an electron from the VB to empty mid-gap states. We assign the broad $750 \mathrm{~nm}$ absorption band, which is similar to the induced absorption band of reduced $\beta-\mathrm{Pb}_{0.33} \mathrm{~V}_{2} \mathrm{O}_{5}$, to the excitation of free CB electrons. Importantly, the TA spectrum of photoexcited $\beta-\mathrm{Pb}_{0.33} \mathrm{~V}_{2} \mathrm{O}_{5}$ is wellmodeled as a linear combination of the absorbance difference spectra associated with electrochemically reduced and oxidized $\beta-\mathrm{Pb}_{0.33} \mathrm{~V}_{2} \mathrm{O}_{5}$ (Fig. $3 \mathrm{~A}$ ), supporting our interpretation of transient absorption bands as arising from the introduction of electrons into the $\mathrm{CB}$ and holes into the mid-gap states. For $\mathrm{V}_{2} \mathrm{O}_{5}$, the bleach at $430 \mathrm{~nm}$ is assigned to a bleach of the ground state absorbance, as exhibited by reduced $\mathrm{V}_{2} \mathrm{O}_{5}$. The absorption band at $535 \mathrm{~nm}$, which is similar to the induced absorption band of oxidized $\mathrm{V}_{2} \mathrm{O}_{5}$, is assigned to the excitation of electrons from deep within the VB to the VB edge.

TA decay traces for $\beta-\mathrm{Pb}_{0.33} \mathrm{~V}_{2} \mathrm{O}_{5}$ and $\mathrm{V}_{2} \mathrm{O}_{5}$ were extracted from transient absorption data matrices by averaging $\triangle \mathrm{A}$ values at a range of probe wavelengths for each delay time. Representative decay traces are shown in Figure 3B and $3 C$. TA decay traces were fit to multiexponential decay kinetics. The smallest number of individual decay lifetimes, $\tau_{i}$, which resulted in the minimum $\chi^{2}$ were used for each fit. All TA decay traces were modeled to biexponential decay kinetics (Eq. 1 with $i=2$ ) except for the decay of the $510 \mathrm{~nm}$ absorption band of $\beta-\mathrm{Pb}_{0.33} \mathrm{~V}_{2} \mathrm{O}_{5}$, for which triexponential decay kinetics (Eq. 1 with $i=3$ ) yielded a substantially improved fit (on the basis of $\chi^{2}$ ). Fitting parameters for all TA decay traces are listed in Tables S1-S3 (Supporting Information). $\mathrm{V}_{2} \mathrm{O}_{5}$ has previously exhibited multiexponential transient absorption decay kinetics due to the presence of distributions of electron and hole trap states that give rise to multiple trap-state recombination mechanisms. ${ }^{40}$

$$
\begin{gathered}
\Delta A=\Delta A_{0}+\sum_{i} A_{i} e^{\left(-t / \tau_{i}\right)} \\
<\tau>=\frac{\sum_{i} A_{i} \tau_{i}}{\sum_{i} A_{i}}
\end{gathered}
$$

TA decay traces reveal differences in kinetics for the various processes occurring in both samples. The decay traces (Fig. 3B and C) and the "color maps" (Fig. 2B and C) reveal clearly that excitons are longerlived in $\beta-\mathrm{Pb}_{0.33} \mathrm{~V}_{2} \mathrm{O}_{5}$ than in $\mathrm{V}_{2} \mathrm{O}_{5}$. Long-lived excitons are advantageous for excited-state charge transfer because charge transfer can compete more effectively with electron-hole recombination. For ease of comparison and discussion of decay kinetics, amplitude-weighted average lifetimes $(<\tau>)$ were computed using Equation 2. For $\beta-\mathrm{Pb}_{0.33} \mathrm{~V}_{2} \mathrm{O}_{5}$, the $510 \mathrm{~nm}$ and $750 \mathrm{~nm}$ TA bands had $\langle\tau>$ of $(2.3 \pm 0.1) \mathrm{x}$ $10^{-7} \mathrm{~s}$ and $(5.9 \pm 0.7) \times 10^{-7} \mathrm{~s}$, respectively. For $\mathrm{V}_{2} \mathrm{O}_{5}$, the $430 \mathrm{~nm}$ bleach and $535 \mathrm{~nm}$ TA band had average lifetimes of $(2.9 \pm 0.5) \times 10^{-7} \mathrm{~s}$ and $(7 \pm 2) \times 10^{-8} \mathrm{~s}$, respectively. A first observation is that the transient absorption band of $\beta-\mathrm{Pb}_{0.33} \mathrm{~V}_{2} \mathrm{O}_{5}$ centered at $750 \mathrm{~nm}$, assigned to excitation of electrons from the midgap states to states above the $C B$ edge, is longer-lived than the bleach observed for $\mathrm{V}_{2} \mathrm{O}_{5}$, suggesting 
that the introduction of the mid-gap states (and the corresponding filled $\mathrm{Pb} 6 \mathrm{~s}-02 \mathrm{p}$ states in the VB) helps to increase the lifetime of the excited electron. A second key observation is that the absorption bands associated with the hole $\left(510 \mathrm{~nm}\right.$ band in $\beta-\mathrm{Pb}_{0.33} \mathrm{~V}_{2} \mathrm{O}_{5}$ and $535 \mathrm{~nm}$ band in $\mathrm{V}_{2} \mathrm{O}_{5}$ ) decay more rapidly than the absorption bands associated with the electron ( $750 \mathrm{~nm}$ band in $\beta-\mathrm{Pb}_{0.33} \mathrm{~V}_{2} \mathrm{O}_{5}$ and $430 \mathrm{~nm}$ bleach in $\mathrm{V}_{2} \mathrm{O}_{5}$ ). Finally, the hole is much longer lived in $\beta-\mathrm{Pb}_{0.33} \mathrm{~V}_{2} \mathrm{O}_{5}$ than in $\mathrm{V}_{2} \mathrm{O}_{5}$. This pronounced difference may arise from different spatial distributions of holes in the two compounds. The photogenerated holes in $\beta-\mathrm{Pb}_{0.33} \mathrm{~V}_{2} \mathrm{O}_{5}$ reside in mid-gap states, which derive primarily from a $\mathrm{Pb} 6 \mathrm{~s}-\mathrm{O}$ $2 p$ interaction and thus are localized on the intercalating $\mathrm{Pb}^{2+}$-ions ${ }^{15}$; in contrast, the photogenerated hole in $\mathrm{V}_{2} \mathrm{O}_{5}$ is situated within the $\mathrm{O} 2 \mathrm{p}$-derived $\mathrm{VB}$ on the $\mathrm{V}_{2} \mathrm{O}_{5}$ framework. ${ }^{41-42}$ For both structures, the electrons reside on $V 3 d$ states in the $C B$ (the $3 d_{x y}$ states are the lowest lying $C B$ states). ${ }^{41-42}$ In other words, the electron-hole wave function overlap is expected to be greater for $\mathrm{V}_{2} \mathrm{O}_{5}$ where both charge carriers are localized on the $\mathrm{V}_{2} \mathrm{O}_{5}$ framework, whereas in $\beta-\mathrm{Pb}_{0.33} \mathrm{~V}_{2} \mathrm{O}_{5}$, the holes are located on the intercalants and the electrons reside on the $\mathrm{V}_{2} \mathrm{O}_{5}$ framework. This spatial separation is likely responsible for the longer exciton lifetimes observed for the latter.

\section{Characterization of $\mathrm{CdSe} / \beta-\mathrm{Pb}_{0.33} \mathrm{~V}_{2} \mathrm{O}_{5}$ and $\mathrm{CdSe} / \mathrm{V}_{2} \mathrm{O}_{5}$ Heterostructures}

Extensive structural characterization of SILAR-derived and LAA-derived (with Cys-CdSe(sm)) CdSe/ $\beta$ $\mathrm{Pb}_{0.33} \mathrm{~V}_{2} \mathrm{O}_{5}$ heterostructures has been reported previously. ${ }^{14}$ Cys-CdSe(sm) QDs, with a narrow first excitonic absorption band centered at $423 \mathrm{~nm}$, are not an optimal choice as solar light harvesters. In this work, we have prepared Cys-CdSe $(\mathrm{Ig}) / \beta-\mathrm{Pb}_{0.33} \mathrm{~V}_{2} \mathrm{O}_{5}$ and $\mathrm{Cys}-\mathrm{CdSe}(\mathrm{lg}) / \mathrm{V}_{2} \mathrm{O}_{5}$ heterostructures using larger Cys-CdSe QDs, which offer greater overlap with the solar spectrum. An absorption spectrum of aqueous dispersed Cys-CdSe(Ig) QDs (Fig. S2, Supporting Information) reveals an absorption onset at 580 $\mathrm{nm}$ with a first-excitonic maximum at $495 \mathrm{~nm}$. Energy-dispersive X-ray spectra (EDS) of Cys-CdSe(Ig)/ $\beta$ $\mathrm{Pb}_{0.33} \mathrm{~V}_{2} \mathrm{O}_{5}$ and $\mathrm{Cys}-\mathrm{CdSe}(\mathrm{Ig}) / \mathrm{V}_{2} \mathrm{O}_{5}$ heterostructures (Fig. S3, Supporting Information) confirm the presence of $\mathrm{Cd}$ and $\mathrm{Se}$ on the nanowires. Average relative amounts of $\mathrm{Cd}, \mathrm{Se}, \mathrm{Pb}$, and $\mathrm{V}$ have been calculated from five spectra, suggesting apparent molecular formulas of $\mathrm{Cd}_{(0.4 \pm 0.1)} \mathrm{Se}_{(0.3 \pm 0.1)} \mathrm{Pb}_{(0.2 \pm .1)} \mathrm{V}_{2} \mathrm{O}_{5}$ and $\mathrm{Cd}_{(0.3 \pm)} \mathrm{Se}_{(0.20 .1 \pm 0.1)} \mathrm{V}_{2} \mathrm{O}_{5}$, respectively for the heterostructures incorporating $\mathrm{Cys}-\mathrm{CdSe}(\mathrm{Ig}) \mathrm{QDs}$.

\section{Transient Absorption Spectra and Dynamics of $\mathrm{CdSe} / \mathrm{\beta}-\mathrm{Pb}_{0.33} \mathrm{~V}_{2} \mathrm{O}_{5}$ and $\mathrm{CdSe} / \mathrm{V}_{2} \mathrm{O}_{5}$ Heterostructures}

$\mathrm{CdSe} / \beta-\mathrm{Pb}_{0.33} \mathrm{~V}_{2} \mathrm{O}_{5}$ heterostructures, synthesized using both LAA and SILAR methods, were characterized with transient absorption spectroscopy. Thin films of $\mathrm{CdSe} / \beta-\mathrm{Pb}_{0.33} \mathrm{~V}_{2} \mathrm{O}_{5}$ heterostructures were excited at $360 \mathrm{~nm}$ and $425 \mathrm{~nm}$ and probed from $425 \mathrm{~nm}$ to $900 \mathrm{~nm}$. These pump wavelengths correspond to above-bandgap excitation for $\beta-\mathrm{Pb}_{0.33} \mathrm{~V}_{2} \mathrm{O}_{5}$ and $\mathrm{V}_{2} \mathrm{O}_{5}$ and to excitation substantially above the bandgap for CdSe QDs (Fig. S2 in Supporting Information). TA spectra were compiled by averaging $\triangle \mathrm{A}$ from $1.5 \mathrm{~ns}$ to $10 \mathrm{~ns}$. Figure $4 A$ and $4 B$ show the results for the heterostructures excited at $360 \mathrm{~nm}$ pump wavelength. Interestingly, $\mathrm{TA}$ spectra of $\mathrm{CdSe} / \beta-\mathrm{Pb}_{0.33} \mathrm{~V}_{2} \mathrm{O}_{5}$ heterostructures are nearly identical to those of $\beta-\mathrm{Pb}_{0.33} \mathrm{~V}_{2} \mathrm{O}_{5}$ nanowires and consist of an intense transient absorption band centered at $500-550 \mathrm{~nm}$ and a less-intense and lower-energy absorption band extending into the near-IR. These spectra are notable for the absence of a bleach of the first excitonic transition of CdSe QDs, which is the wellestablished spectral signature of CdSe QDs on time scales greater than $10^{-9} \mathrm{~s},{ }^{43-45}$ and was the dominant feature of our measured TA spectrum of dispersed aqueous Cys-CdSe(Ig) QDs (Fig. S4 in Supporting 

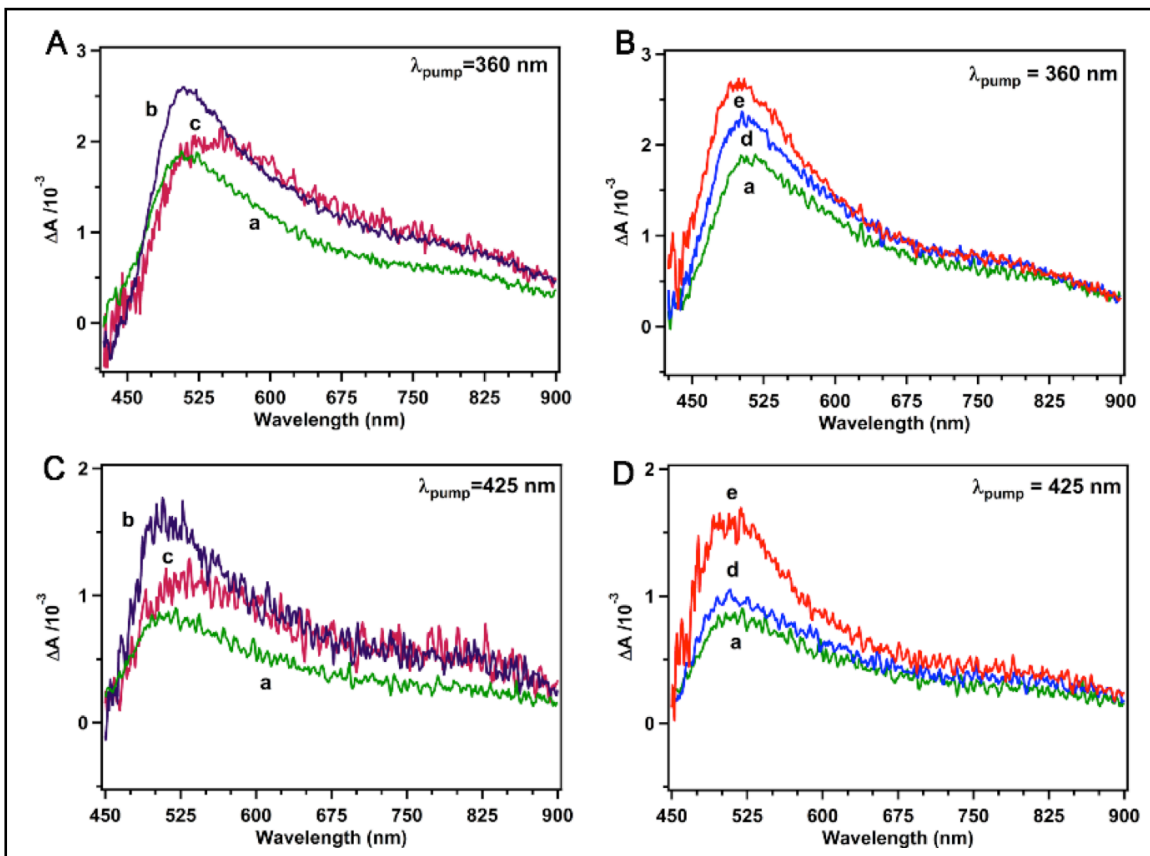

Figure 4. TA spectra of (a) $\beta-\mathrm{Pb}_{0.33} \mathrm{~V}_{2} \mathrm{O}_{5}$; (b) $1 x \mathrm{SILAR} C d S e / \beta-\mathrm{Pb}_{0.33} \mathrm{~V}_{2} \mathrm{O}_{5}$; (c) $3 x$ SILAR CdSe $/ \beta-\mathrm{Pb}_{0.33} \mathrm{~V}_{2} \mathrm{O}_{5}$; (d) Cys-CdSe(sm)/ $\beta-\mathrm{Pb}_{0.33} \mathrm{~V}_{2} \mathrm{O}_{5}$; and (e) Cys-CdSe(lg)/ $\beta$ $\mathrm{Pb}_{0.33} \mathrm{~V}_{2} \mathrm{O}_{5}$ with $\lambda_{\text {pump }}=360 \mathrm{~nm}$ and $425 \mathrm{~nm}$.

Information). Thus, excitation of either CdSe QDs or $\beta-\mathrm{Pb}_{0.33} \mathrm{~V}_{2} \mathrm{O}_{5}$ nanowires within the heterostructures yielded a TA spectrum associated with electron-hole pairs localized in the $\beta$ $\mathrm{Pb}_{0.33} \mathrm{~V}_{2} \mathrm{O}_{5}$ nanowires. The most notable difference in the TA spectra of $\mathrm{CdSe} / \beta$ $\mathrm{Pb}_{0.33} \mathrm{~V}_{2} \mathrm{O}_{5}$ heterostructures relative to the bare $\beta-\mathrm{Pb}_{0.33} \mathrm{~V}_{2} \mathrm{O}_{5}$ nanowires is that the spectra of heterostructures exhibit a substantial amplification

of the absorption bands. This enhanced amplitude (increased $\Delta \mathrm{A}$ ) suggests an increase in exciton concentration in the $\beta-\mathrm{Pb}_{0.33} \mathrm{~V}_{2} \mathrm{O}_{5}$ nanowires arising from both hole and electron injection (exciton diffusion) from the CdSe QDs. In other words, apart from the native exciton population generated by direct excitation of $\beta-\mathrm{Pb}_{0.33} \mathrm{~V}_{2} \mathrm{O}_{5}$, exciton diffusion from photoexcited CdSe QDs, which is thermodynamically favorable (Fig. 1), further increases the exciton population of underlying nanowires. This behavior is agnostic of the nature of the interfaces and is observed for both the LAA and SILAR heterostructures.

The higher-energy and more intense absorption band in the TA spectrum of $3 \times$ SILAR CdSe/ $\beta-\mathrm{Pb}_{0.33} \mathrm{~V}_{2} \mathrm{O}_{5}$ heterostructures (spectrum $c$ in Fig. 4 ) is red-shifted relative to those of $1 \times$ SILAR CdSe $/ \beta-\mathrm{Pb}_{0.33} \mathrm{~V}_{2} \mathrm{O}_{5}$ heterostructures (spectrum $\mathrm{b}$ in Fig. 4 ) and $\beta-\mathrm{Pb}_{0.33} \mathrm{~V}_{2} \mathrm{O}_{5}$ nanowires (spectrum a in Fig. 4). This apparent red-shift may have arisen from the increased contribution of the ground-state bleach of CdSe, since the $3 \times$ SILAR sample has a significantly higher ratio of $\mathrm{CdSe} Q \mathrm{QDs}$ to $\beta-\mathrm{Pb}_{0.33} \mathrm{~V}_{2} \mathrm{O}_{5}$ nanowires. If an appreciable fraction of QDs was not in direct contact with the nanowire surface, as observed previously ${ }^{14}$, then such QDs would probably not transfer charge carriers efficiently to the nanowires, resulting in some contribution of the excitonic bleach of CdSe to the overall measured TA spectrum.

TA spectra of $\mathrm{CdSe} / \beta-\mathrm{Pb}_{0.33} \mathrm{~V}_{2} \mathrm{O}_{5}$ heterostructures and bare $\beta-\mathrm{Pb}_{0.33} \mathrm{~V}_{2} \mathrm{O}_{5}$ nanowires acquired with $425 \mathrm{~nm}$ excitation were also nearly identical but with higher $\triangle \mathrm{A}$ values for the QD-coated samples. The amplified absorption bands associated with the nanowire-localized excitons can again be attributed to exciton diffusion from CdSe QDs to $\beta-\mathrm{Pb}_{0.33} \mathrm{~V}_{2} \mathrm{O}_{5}$ nanowires. 
TA spectra of $\mathrm{CdSe} / \mathrm{V}_{2} \mathrm{O}_{5}$ heterostructures were collected as a set of control experiments. Hole transfer from $\mathrm{CdSe}$ to $\mathrm{V}_{2} \mathrm{O}_{5}$ is thermodynamically disfavored, whereas electron injection from photoexcited CdSe to $\mathrm{V}_{2} \mathrm{O}_{5}$ is feasible based on the relative energy positioning of the $\mathrm{CB}$ edges of $\mathrm{CdSe}$ and $\mathrm{V}_{2} \mathrm{O}_{5}$ (Fig. 1). Films of $\mathrm{V}_{2} \mathrm{O}_{5}$ and $\mathrm{CdSe} / \mathrm{V}_{2} \mathrm{O}_{5}$ heterostructures were excited at $360 \mathrm{~nm}$ and $600 \mathrm{~nm}$ and probed between
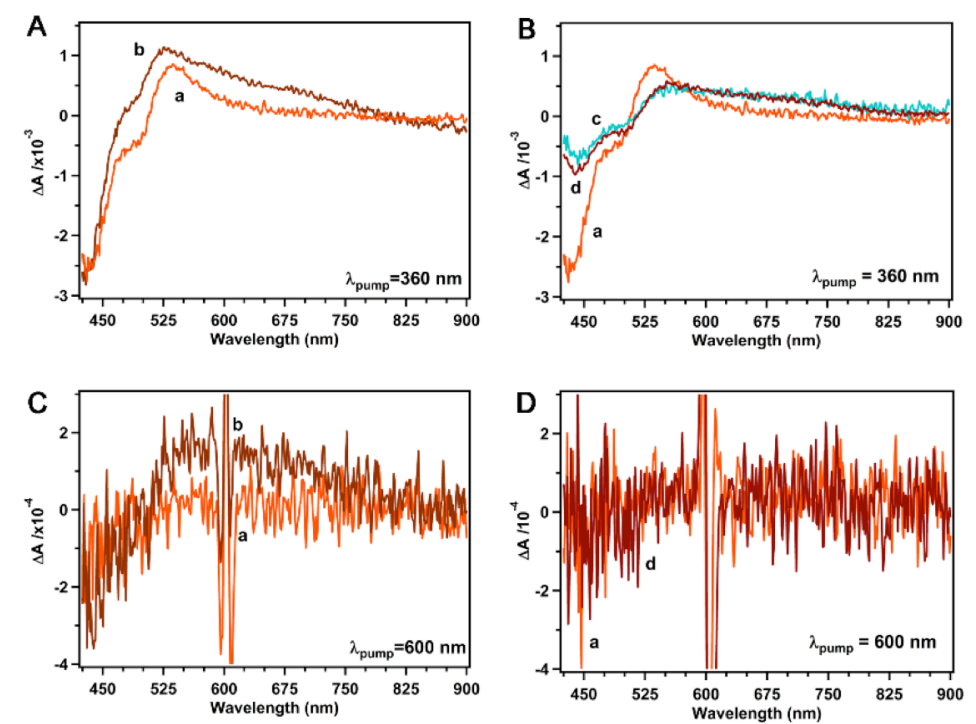

Figure 5. TA spectra of (a) $\mathrm{V}_{2} \mathrm{O}_{5}$, (b) $5 x$ SILAR CdSe $/ \mathrm{V}_{2} \mathrm{O}_{5}$, (c) Cys$\mathrm{CdSe}(\mathrm{sm}) / \mathrm{V}_{2} \mathrm{O}_{5}$, and (d) Cys-CdSe $(\mathrm{lg}) / \mathrm{V}_{2} \mathrm{O}_{5}$ with $\lambda_{\text {pump }}=360 \mathrm{~nm}$ and 600 $\mathrm{nm}$.
$425 \mathrm{~nm}$ and $900 \mathrm{~nm}$, and TA spectra were compiled by averaging $\triangle \mathrm{A}$ from 1.5 to $10 \mathrm{~ns}$. The $5 x \quad$ SILAR $\quad \mathrm{CdSe} / \mathrm{V}_{2} \mathrm{O}_{5}$ heterostructures were chosen because the coverage of QDs on $\mathrm{V}_{2} \mathrm{O}_{5}$ nanowires was similar to the coverage of QDs on $\beta$ $\mathrm{Pb}_{0.33} \mathrm{~V}_{2} \mathrm{O}_{5}$ nanowires in $1 \times$ SILAR $\mathrm{CdSe} / \beta-\mathrm{Pb}_{0.33} \mathrm{~V}_{2} \mathrm{O}_{5}$ heterostructures, as verified by energy dispersive X-ray analysis. ${ }^{14}$ TA spectra of $\mathrm{CdSe} / \mathrm{V}_{2} \mathrm{O}_{5}$ heterostructures differ significantly from the TA spectrum of $\mathrm{V}_{2} \mathrm{O}_{5}$ and furthermore exhibit substantial differences depending on the nature of the interface (Fig. 5). First, in TA spectra acquired with

excitation at $360 \mathrm{~nm}$ (Fig. 5A, B), the CdSe/ $\mathrm{V}_{2} \mathrm{O}_{5}$ heterostructures synthesized by both SILAR and LAA exhibit a transient absorption band centered at 525-545 nm, which is shifted and broadened significantly to long wavelengths relative to the 535-nm absorption band of $\mathrm{V}_{2} \mathrm{O}_{5}$. The band is less intense for $\mathrm{CdSe} / \mathrm{V}_{2} \mathrm{O}_{5}$ heterostructures prepared by LAA than for those prepared by SILAR. Second, the transient absorption band of $\mathrm{CdSe} / \mathrm{V}_{2} \mathrm{O}_{5}$ heterostructures is much more intense than that of $\mathrm{V}_{2} \mathrm{O}_{5}$ nanowires beyond $575 \mathrm{~nm}$ and extends into the near-IR. TA spectra of $\mathrm{V}_{2} \mathrm{O}_{5}$ nanowires and of Cys$\mathrm{CdSe}(\mathrm{Ig}) / \mathrm{V}_{2} \mathrm{O}_{5}$ heterostructures prepared by LAA were featureless when acquired with excitation at 600 $\mathrm{nm}$ (Fig. 5C, D), because $600 \mathrm{~nm}$ light is insufficiently energetic to excite the band-gap transition of $\mathrm{V}_{2} \mathrm{O}_{5}$ nanowires or Cys-CdSe(lg) QDs (Fig. S2). In contrast, the TA spectrum of $5 x$ SILAR CdSe/ $\mathrm{V}_{2} \mathrm{O}_{5}$ heterostructures, acquired with excitation at $600 \mathrm{~nm}$, exhibits a long-wavelength absorption band similar to that observed upon excitation at $360 \mathrm{~nm}$. This long-wavelength absorption band is noteworthy and facilitates spectral assignments. We attribute this feature, which extends to ca. $750 \mathrm{~nm}$, to an absorption associated with trapped holes in CdSe QDs, consistent with reported assignments of TA spectra of oxidized CdSe QDs. ${ }^{46}$ The presence of a trapped hole suggests that photoexcitation of the QDs is followed by electron transfer to $\mathrm{V}_{2} \mathrm{O}_{5}$, which is thermodynamically favorable (Fig. 1). Transfer of the photogenerated hole from CdSe to the $\mathrm{VB}$ of $\mathrm{V}_{2} \mathrm{O}_{5}$ is thermodynamically uphill (Fig. 1); thus, the hole apparently remains in the QD where it is confined in surface-localized trap states. The long-wavelength absorption band in the TA spectra of $\mathrm{CdSe} / \mathrm{V}_{2} \mathrm{O}_{5}$ heterostructures acquired with $360 \mathrm{~nm}$ excitation (Fig. 
$5 \mathrm{~A}, \mathrm{~B}$ ) can thus also be similarly assigned. The shift of the TA band centered at $535 \mathrm{~nm}$ for $\mathrm{V}_{2} \mathrm{O}_{5}$ can now be assigned to an increased proportion of reduced $\mathrm{V}_{2} \mathrm{O}_{5}$ in the heterostructures as a result of electron transfer from the photoexcited QDs (Fig. S1). In addition, the superposition of a bleach from photoexcited QDs at probe wavelengths of $475-540 \mathrm{~nm}$ (Fig. S4) probably also contributed to the observed shift of the maximum of the net transient absorption centered at 525-545 nm. Since the 600 $\mathrm{nm}$ pump pulse was insufficiently energetic to excite Cys-CdSe(Ig) QDs, it is not surprising that TA spectrum $c$ in Figure 5D suggests no evidence for charge transfer. In contrast, the $\mathrm{CdSe} / \mathrm{V}_{2} \mathrm{O}_{5}$ heterostructures prepared by SILAR have a broader size distribution including larger nanocrystal sizes that likely allow for photoexcitation of a fraction of the QDs, enabling electron transfer to $\mathrm{V}_{2} \mathrm{O}_{5}$ and giving rise to the broad long-wavelength absorption associated with the hole in CdSe observed in Figure 5C. TA spectra acquired for these samples at pump wavelengths of 425 and $490 \mathrm{~nm}$, both of which are more energetic than the band gap of CdSe QDs, are shown in Figure S5 in Supporting Information. The TA spectra of $\mathrm{CdSe} / \mathrm{V}_{2} \mathrm{O}_{5}$ heterostructures prepared by LAA and SILAR are markedly different. TA spectra for the SILAR-derived samples exhibit characteristic spectral signatures of electron transfer, whereas TA spectra of the LAA-derived samples are unmodified from that of $\mathrm{V}_{2} \mathrm{O}_{5}$ revealing the absence of electron transfer. These findings suggest that following excitation at $360 \mathrm{~nm}$, hot electrons can be injected across the interfaces defined by the molecular linker but electrons excited to the CB edge are not energetic enough to diffuse across the interface. In contrast, electron transfer is observed following excitation at all pump wavelengths for the SILAR-derived interface.
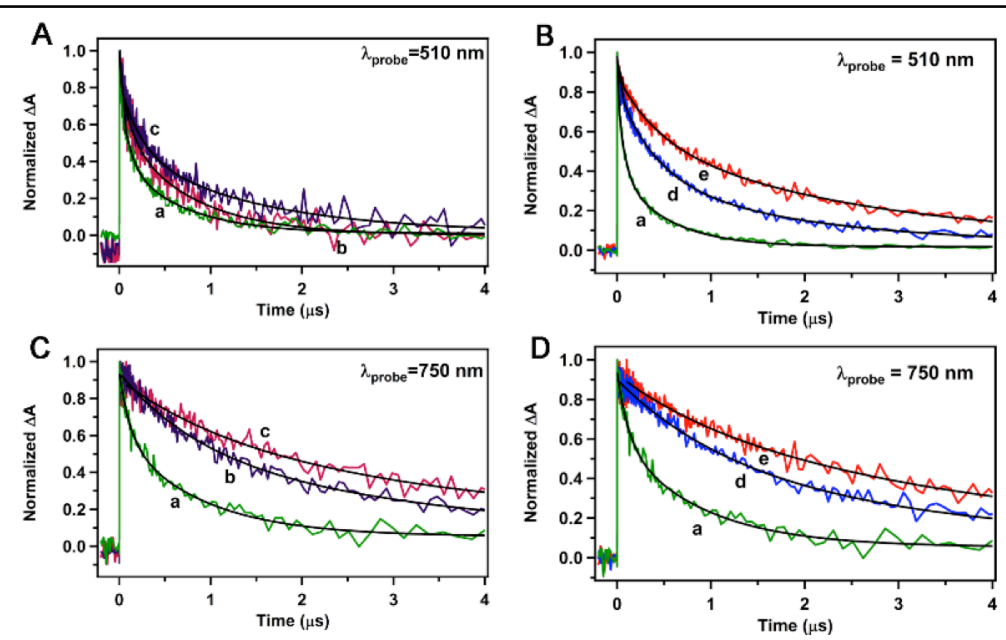

Figure 6. TA decay traces and fits for (a) $\beta-\mathrm{Pb}_{0.33} \mathrm{~V}_{2} \mathrm{O}_{5}$, (b) $1 \times$ SILAR $\mathrm{CdSe} / \beta-\mathrm{Pb}_{0.33} \mathrm{~V}_{2} \mathrm{O}_{5}$, (c) $3 \times \mathrm{SILAR} \mathrm{CdSe} / \beta-\mathrm{Pb}_{0.33} \mathrm{~V}_{2} \mathrm{O}_{5}$, (d) $\mathrm{Cys}-\mathrm{CdSe}(\mathrm{sm}) / \beta$ $\mathrm{Pb}_{0.33} \mathrm{~V}_{2} \mathrm{O}_{5}$, and (e) Cys-CdSe(lg)/ $\beta-\mathrm{Pb}_{0.33} \mathrm{~V}_{2} \mathrm{O}_{5}$ at probe wavelengths of 510 and $750 \mathrm{~nm}$ with $\lambda_{\text {pump }}=360 \mathrm{~nm}$.

TA decay traces of $\mathrm{CdSe} / \beta$ $\mathrm{Pb}_{0.33} \mathrm{~V}_{2} \mathrm{O}_{5}$ samples pumped at $360 \mathrm{~nm}$ are shown in Figure 6. TA decay traces of the $510 \mathrm{~nm}$ absorption band were wellmodeled with triexponential kinetics, and decay traces of the $750 \mathrm{~nm}$ band were well-modeled with biexponential kinetics. Tables S1 and S2 in the Supporting information list fitting parameters and calculated average lifetimes. Upon functionalization of $\beta-\mathrm{Pb}_{0.33} \mathrm{~V}_{2} \mathrm{O}_{5}$ with CdSe QDs via both SILAR and LAA deposition methods, values of $\langle\tau\rangle$ for both the $510 \mathrm{~nm}$ and $750 \mathrm{~nm}$ transient absorption bands increased relative to uncoated $\beta-\mathrm{Pb}_{0.33} \mathrm{~V}_{2} \mathrm{O}_{5}$. For the $510 \mathrm{~nm}$ band, $\langle\tau\rangle$ increased by approximately 3-fold for SILAR-deposited $\mathrm{CdSe} / \beta-\mathrm{Pb}_{0.33} \mathrm{~V}_{2} \mathrm{O}_{5}$. LAA-derived samples exhibited greater increases in $\langle\tau\rangle$ of approximately 3.9- and 6.5 -fold for $\mathrm{Cys}-\mathrm{CdSe}(\mathrm{sm}) / \beta-\mathrm{Pb}_{0.33} \mathrm{~V}_{2} \mathrm{O}_{5}$ and $\mathrm{Cys}-\mathrm{CdSe}(\mathrm{Ig}) / \beta-\mathrm{Pb}_{0.33} \mathrm{~V}_{2} \mathrm{O}_{5}$ heterostructures, respectively. The value of $\langle\tau\rangle$ for the $750 \mathrm{~nm}$ absorption band increased by 
approximately 5 -fold for $\mathrm{CdSe} / \beta-\mathrm{Pb}_{0.33} \mathrm{~V}_{2} \mathrm{O}_{5}$ prepared using both deposition methods. Observed increases in exciton lifetimes for $\mathrm{CdSe} / \beta-\mathrm{Pb}_{0.33} \mathrm{~V}_{2} \mathrm{O}_{5}$ are attributed to surface passivation of $\beta-\mathrm{Pb}_{0.33} \mathrm{~V}_{2} \mathrm{O}_{5}$ nanowires by the CdSe QDs and the elimination of surface trap states and trap state-mediated electronhole recombination pathways.

TA decay traces of $\mathrm{CdSe} / \mathrm{V}_{2} \mathrm{O}_{5}$ samples pumped at $360 \mathrm{~nm}$ are shown in Figure 7. All decay traces were well-modeled by biexponential kinetics; fitting parameters and average lifetimes are compiled in Table $\mathrm{S} 3$ in Supporting Information. Deposition of CdSe QDs onto $\mathrm{V}_{2} \mathrm{O}_{5}$ nanowires by both SILAR and LAA had minimal impact on the decay kinetics of the 440-nm bleach. Values of $\langle\tau\rangle$ for the bleach for $\mathrm{CdSe} / \mathrm{V}_{2} \mathrm{O}_{5}$ heterostructures ranged from $70 \%$ to $150 \%$ of $\langle\tau\rangle$ for $\mathrm{V}_{2} \mathrm{O}_{5}$ nanowires. Deposition of $\mathrm{CdSe}$ had a somewhat greater impact on decay kinetics of the $535 \mathrm{~nm}$ absorption band. For SILAR-derived heterostructures, $\langle\tau\rangle$ for the absorption increased by approximately 3.3 -fold relative to $\mathrm{V}_{2} \mathrm{O}_{5}$ nanowires. For LAA-derived $\mathrm{CdSe} / \mathrm{V}_{2} \mathrm{O}_{5}$ heterostructures, $\langle\tau\rangle$ decreased by approximately 1.6 -fold for $\mathrm{Cys}$-CdSe(sm) and increased by approximately 2 -fold for Cys-CdSe(lg). Similarly to the $\mathrm{CdSe} / \beta-\mathrm{Pb}_{0.33} \mathrm{~V}_{2} \mathrm{O}_{5}$ heterostructures, the increase of $\langle\tau>$ upon SILAR deposition of CdSe or LAA of Cys-CdSe(Ig) QDs may have arisen from passivation of surface trap states on $\mathrm{V}_{2} \mathrm{O}_{5}$ nanowires.

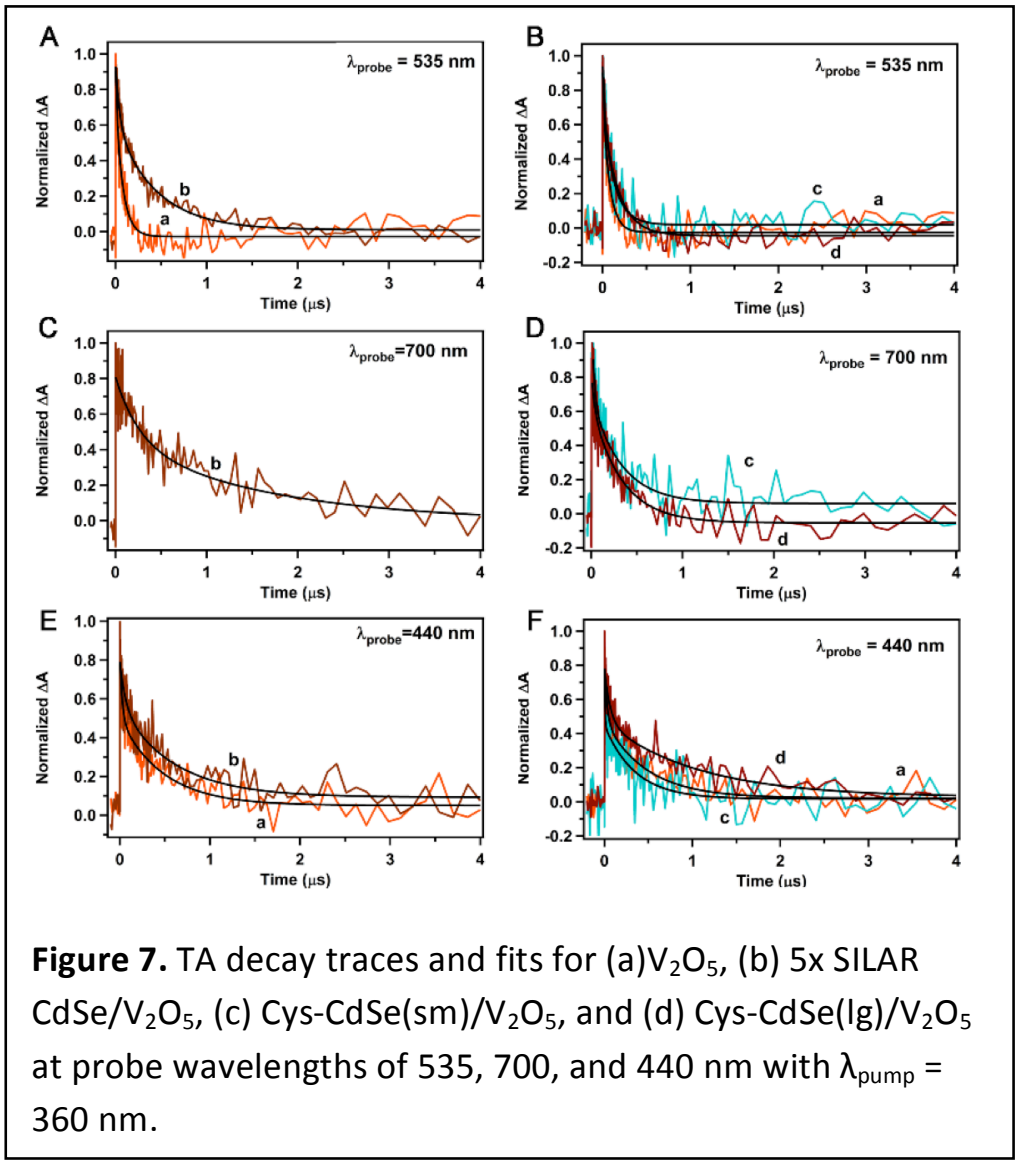

TA decay traces of the longwavelength transient absorption band observed for both SILAR- and LAA-derived $\mathrm{CdSe} / \mathrm{V}_{2} \mathrm{O}_{5}$ are shown in Figure 7C,D. As discussed earlier, the induced absorption observed exclusively for $\mathrm{CdSe} / \mathrm{V}_{2} \mathrm{O}_{5}$ is assigned to trapped holes in oxidized CdSe QDs produced by the excited-state transfer of an electron from CdSe to $\mathrm{V}_{2} \mathrm{O}_{5}{ }^{46}$ Average lifetimes of (1.0 \pm $0.8) \times 10^{-6} \mathrm{~s},(1.7 \pm 0.6) \times 10^{-7} \mathrm{~s}$ and $(2.7 \pm 0.7) \times 10^{-7} \mathrm{~s}$ were determined for this long-wavelength absorption band of $5 x$ SILAR CdSe $/ \mathrm{V}_{2} \mathrm{O}_{5}$, LAAderived Cys-CdSe(sm) $/ \mathrm{V}_{2} \mathrm{O}_{5}$, and LAA-derived Cys-CdSe(Ig)/ $\mathrm{V}_{2} \mathrm{O}_{5}$ heterostructures, respectively. This absorption band is longer-lived than the $535-\mathrm{nm}$ absorption band of uncoated $\mathrm{V}_{2} \mathrm{O}_{5}\left((7 \pm 2) \times 10^{-8} \mathrm{~s}\right)$ and the excitonic bleach of dispersed Cys-CdSe(lg) QDs ((5.9 \pm 0.2$\left.) \times 10^{-8} \mathrm{~s}\right)$ (Fig. S4, Supporting Information), supporting our assignment of the 
band to a charge-separated state. The lifetimes of the $535-\mathrm{nm}$ absorption band of uncoated $\mathrm{V}_{2} \mathrm{O}_{5}$ and the bleach of dispersed Cys-CdSe(lg) QDs are associated with a bound exciton. Charge-separated states are typically longer-lived than bound excitons as the spatial separation between electron and hole is greater resulting in diminished overlap of their respective wave functions. ${ }^{5,12,47}$

\section{Ultra-fast Dynamics}

Ultra-fast transient absorption measurements were performed to examine exciton dynamics on a picosecond timescale and to directly observe charge-transfer processes. TA difference spectra for $\beta$ $\mathrm{Pb}_{0.33} \mathrm{~V}_{2} \mathrm{O}_{5}$, 3x SILAR CdSe/ $\beta-\mathrm{Pb}_{0.33} \mathrm{~V}_{2} \mathrm{O}_{5}$, and $\mathrm{Cys}-\mathrm{CdSe}(\mathrm{lg}) / \beta-\mathrm{Pb}_{0.33} \mathrm{~V}_{2} \mathrm{O}_{5}$ were extracted at 1-ps intervals over the first $5 \mathrm{ps}$ following excitation (Fig. 8). For $\beta-\mathrm{Pb}_{0.33} \mathrm{~V}_{2} \mathrm{O}_{5}$ nanowires, the transient absorption bands reached maximum amplitude within the instrument response time, as expected for TA signals derived from the direct photogeneration of an exciton in $\beta-\mathrm{Pb}_{0.33} \mathrm{~V}_{2} \mathrm{O}_{5}$. For $3 x \mathrm{SILAR} C d S e / \beta-\mathrm{Pb}_{0.33} \mathrm{~V}_{2} \mathrm{O}_{5}$ and Cys-CdSe(lg)/ $\beta-\mathrm{Pb}_{0.33} \mathrm{~V}_{2} \mathrm{O}_{5}$, the shorter-wavelength band appears to be at full intensity within the temporal resolution of the measurement; however, a distinct progressive rise of $\Delta \mathrm{A}$ amplitude in the longer-wavelength region of the absorption band is discernible. The growth of the absorption for $3 x$ SILAR CdSe/ $\beta-\mathrm{Pb}_{0.33} \mathrm{~V}_{2} \mathrm{O}_{5}$ has been measured from approximately 525 to $650 \mathrm{~nm}$, appearing as a broad growth of the entire longer-wavelength half of the absorption band. The rise in $\triangle \mathrm{A}$ for $\mathrm{Cys}-\mathrm{CdSe}(\mathrm{lg}) / \beta$ $\mathrm{Pb}_{0.33} \mathrm{~V}_{2} \mathrm{O}_{5}$ spanned a smaller wavelength range, from approximately 490 to $575 \mathrm{~nm}$, with a local $\Delta \mathrm{A}$ minimum at $535 \mathrm{~nm}$ in the TA spectra acquired at the shortest delay times of 1 and $5 \mathrm{ps}$.

The rise of $\Delta \mathrm{A}$ across a specific spectral range, observed only upon interfacing with CdSe QDs, is logically attributed to contributions to the observed TA spectra from the decay of the bleach associated with the first excitonic ground-state absorption of the QDs. Considering that TA spectra of $C d S e / \beta-\mathrm{Pb}_{0.33} \mathrm{~V}_{2} \mathrm{O}_{5}$ are
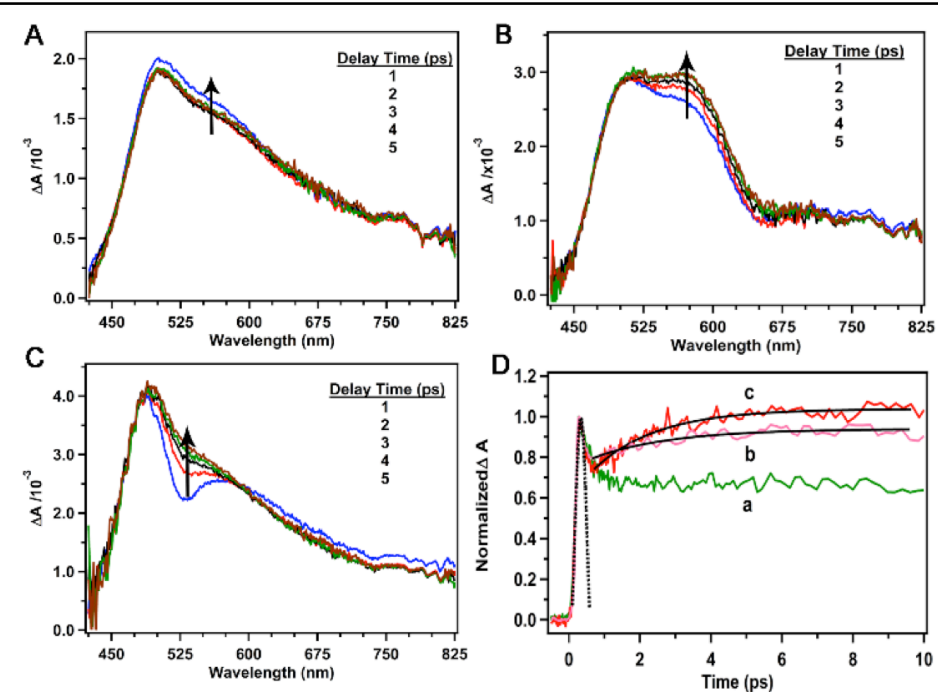

Figure 8. Ultra-fast TA spectra of $(A) \beta-\mathrm{Pb}_{0.33} \mathrm{~V}_{2} \mathrm{O}_{5},(\mathrm{~B}) 3 \times \mathrm{SILAR}$ $\mathrm{CdSe} / \beta-\mathrm{Pb}_{0.33} \mathrm{~V}_{2} \mathrm{O}_{5}$, and (C) Cys-CdSe(lg) $/ \beta-\mathrm{Pb}_{0.33} \mathrm{~V}_{2} \mathrm{O}_{5}$ with $\lambda_{\text {pump }}=$ $360 \mathrm{~nm}$, and corresponding TA decay traces (D) for (a) $\beta$ $\mathrm{Pb}_{0.33} \mathrm{~V}_{2} \mathrm{O}_{5}$, (b) $3 \times \mathrm{SILAR} \mathrm{CdSe} / \beta-\mathrm{Pb}_{0.33} \mathrm{~V}_{2} \mathrm{O}_{5}$ and (c) $\mathrm{Cys}-\mathrm{CdSe}(\mathrm{lg}) / \beta$ $\mathrm{Pb}_{0.33} \mathrm{~V}_{2} \mathrm{O}_{5}$. A Gaussian model of the excitation laser pulse is superimposed on the TA decay traces. a combination of the signal from photoexcited $\beta-\mathrm{Pb}_{0.33} \mathrm{~V}_{2} \mathrm{O}_{5}$ and $\mathrm{CdSe}$, the CdSe bleach can reasonably be expected to contribute to the total measured $\Delta \mathrm{A}$. Figure S4 (Supporting Information) depicts a TA spectrum and decay trace of Cys-CdSe(lg) QDs dispersed in $\mathrm{H}_{2} \mathrm{O}$. A bleach of the ground-state absorption is observed, with an onset at $575 \mathrm{~nm}$ and a minimum at $516 \mathrm{~nm}$ and shoulder minimum at $445 \mathrm{~nm}$, corresponding to the first and second excitonic bands, respectively. ${ }^{43-45}$ Indeed, the shape and position of the bleach are quite similar to the shape and position of the $\Delta \mathrm{A}$ minimum observed in the TA spectrum of Cys$\mathrm{CdSe}(\lg ) \beta-\mathrm{Pb}_{0.33} \mathrm{~V}_{2} \mathrm{O}_{5}$ (Fig. $8 \mathrm{C}$ ) at short 
delay times. As the $\mathrm{CdSe}$ bleach decays, its contribution to the total $\triangle \mathrm{A}$ decreases and a net rise in $\Delta \mathrm{A}$ is observed. It should be noted that a well-resolved bleach band was not observed in the TA spectrum of the SILAR-prepared sample due to a wide distribution of particle sizes inherent to the deposition method. ${ }^{26}$ The broad rise in $\triangle \mathrm{A}$ intensity observed is similar to what one would expect based on the ground-state absorbance of SILAR CdSe QDs on $\beta-\mathrm{Pb}_{0.33} \mathrm{~V}_{2} \mathrm{O}_{5}$ as shown in Figure $\mathrm{S} 2$ of the supporting information.

Apart from the contribution from the CdSe bleach, the transient absorption band appears to be at maximal amplitude instantaneously for both $\mathrm{CdSe} / \beta-\mathrm{Pb}_{0.33} \mathrm{~V}_{2} \mathrm{O}_{5}$ samples. As discussed earlier, this absorption band is associated with a hole located in the mid-gap states of $\beta-\mathrm{Pb}_{0.33} \mathrm{~V}_{2} \mathrm{O}_{5}$ nanowires and corresponds to excitation of an electron from deeper $V B$ states. Therefore, we conclude that hole transfer from the $\mathrm{VB}$ of $\mathrm{CdSe}$ into the mid-gap states of $\beta-\mathrm{Pb}_{0.33} \mathrm{~V}_{2} \mathrm{O}_{5}$ must occur within the excitation pulse. If the hole transfer reaction were slower, one would expect the absorption band to grow as hole transfer occurred. In contrast, the time-resolvable decay of the first excitonic bleaches of $\mathrm{CdSe}(\mathrm{lg})$ and SILAR-derived CdSe QDs, suggests that the transfer of electrons to the $\mathrm{CB}$ of $\beta-\mathrm{Pb}_{0.33} \mathrm{~V}_{2} \mathrm{O}_{5}$ occurs more slowly than the transfer of holes to the mid-gap states. Ultra-fast TA decay traces (Fig. 8D) show the rise in $\triangle \mathrm{A}$ associated with $\mathrm{CdSe}$ bleach decay. The rise in $\Delta \mathrm{A}$ intensity can be fit to a single exponential function, and lifetimes of $(2.3 \pm 0.3) \times 10^{-12} \mathrm{~s}$ and $(1.8 \pm 0.1) \times 10^{-12} \mathrm{~s}$ are obtained for $3 \times$ SILAR CdSe/ $\beta$ $\mathrm{Pb}_{0.33} \mathrm{~V}_{2} \mathrm{O}_{5}$ and $\mathrm{Cys}-\mathrm{CdSe}(\mathrm{lg}) / \beta-\mathrm{Pb}_{0.33} \mathrm{~V}_{2} \mathrm{O}_{5}$, respectively. These lifetimes can be attributed to the tail-end of electron transfer from the $\mathrm{CB}$ edges of photoexcited $\mathrm{CdSe} Q \mathrm{QD}$ into the $\mathrm{CB}$ edge of $\beta-\mathrm{Pb}_{0.33} \mathrm{~V}_{2} \mathrm{O}_{5}$. Importantly, the bleach of free Cys-CdSe(lg) QDs, for which electron-hole recombination is the only deactivation pathway, decays with an average lifetime of $(5.9 \pm 0.2) \times 10^{-8} \mathrm{~s}$. Thus, the vastly accelerated bleach decays for the $\mathrm{CdSe} / \beta-\mathrm{Pb}_{0.33} \mathrm{~V}_{2} \mathrm{O}_{5}$ samples, which give rise to the time-resolvable growth of the net absorption, are entirely consistent with a mechanism in which rapid electron transfer competes with intra-QD electron-hole recombination.

\section{Conclusions}

Transient absorption spectroscopy measurements of $\mathrm{CdSe} / \mathrm{\beta}-\mathrm{Pb}_{0.33} \mathrm{~V}_{2} \mathrm{O}_{5}$ heterostructures prepared by LAA and SILAR have provided compelling evidence that electrons and holes were transferred from photoexcited CdSe QDs into the $C B$ and mid-gap states, respectively, of $\beta-\mathrm{Pb}_{0.33} \mathrm{~V}_{2} \mathrm{O}_{5}$ nanowires. In stark contrast, for $\mathrm{CdSe} / \mathrm{V}_{2} \mathrm{O}_{5}$ heterostructures, only electron transfer from photoexcited QDs to $\mathrm{CB}$ states of $\mathrm{V}_{2} \mathrm{O}_{5}$ was observed. Ultra-fast transient absorption measurements of $\mathrm{CdSe} / \mathrm{\beta}-\mathrm{Pb}_{0.33} \mathrm{~V}_{2} \mathrm{O}_{5}$ heterostructures suggest that holes were transferred more rapidly than electrons. The efficient extraction of holes from photoexcited CdSe QDs (as required for applications such as water oxidation) can thus be facilitated by the presence of mid-gap states derived from intercalative cations.

Distinctive electron transfer dynamics were observed for $\mathrm{CdSe} / \mathrm{V}_{2} \mathrm{O}_{5}$ heterostructures depending on the nature of the interface. Electron transfer from CdSe QDs to $\beta-\mathrm{Pb}_{0.33} \mathrm{~V}_{2} \mathrm{O}_{5}$ nanowires occurred readily for heterostructures assembled via SILAR with direct interfaces; however, for heterostructures prepared by 
LAA and interfaced using molecular linkers, electron transfer was observed only for hot electrons produced with excitation at energies significantly greater than the band-gap of CdSe.

The results presented here demonstrate that charge transfer from photoexcited CdSe QDs to $\beta$ $\mathrm{Pb}_{0.33} \mathrm{~V}_{2} \mathrm{O}_{5}$ nanowires can compete successfully with electron-hole recombination pathways, suggesting the feasibility of using intercalative mid-gap states as acceptors of photogenerated holes. Such an approach would represent a fundamentally distinct design principle for enhancing charge transfer across interfaces. Future work will focus on the development of $\mathrm{CdSe} / \beta-\mathrm{Pb}_{0.33} \mathrm{~V}_{2} \mathrm{O}_{5}$ hybrid photocathodes by incorporating an electron acceptor into the heterostructure, such that electron transfer to the acceptor might compete with electron injection into the $\mathrm{CB}$ of $\beta-\mathrm{Pb}_{0.33} \mathrm{~V}_{2} \mathrm{O}_{5}$.

\section{Acknowledgments}

This work was funded by the Research Corporation for Science Advancement through a Scialog Award. KEP and SB also acknowledge partial support from the National Science Foundation under DMR 1504702. This research used resources of the Center for Functional Nanomaterials, which is a U.S. DOE Office of Science Facility, at Brookhaven National Laboratory under Contract No. DE-SC0012704.

\section{References}

1. Gratzel, M., Nature (London, United Kingdom) 2001, 414 (6861), 338-344.

2. Semonin, O. E.; Luther, J. M.; Beard, M. C., Materials Today (Oxford, United Kingdom) 2012, 15 (11), 508-515.

3. Kamat, P. V., Journal of Physical Chemistry Letters 2013, 4 (6), 908-918.

4. Nocera, D. G., Accounts of Chemical Research 2012, 45 (5), 767-776.

5. Kamat, P. V., Journal of Physical Chemistry C 2008, 112 (48), 18737-18753.

6. Nozik, A. J., Physica E: Low-Dimensional Systems \& Nanostructures (Amsterdam, Netherlands) 2002, 14 (1-2), 115-120.

7. Bridewell, V. L.; Alam, R.; Karwacki, C. J.; Kamat, P. V., Chemistry of Materials 2015, 27 (14), 5064-5071.

8. $\quad$ Kamat, P. V., Accounts of Chemical Research 2012, 45 (11), 1906-1915.

9. Pandey, A.; Guyot-Sionnest, P., Science (Washington, DC, United States) 2008, 322 (5903), 929932.

10. Nagpal, P.; Klimov, V. I., Nature Communications 2011, 2 (Sept.), 1492/1-1492/7.

11. Goodman, S. M.; Singh, V.; Ribot, J. C.; Chatterjee, A.; Nagpal, P., Journal of Physical Chemistry Letters 2014, 5 (21), 3909-3913.

12. Selinsky, R. S.; Ding, Q.; Faber, M. S.; Wright, J. C.; Jin, S., Chemical Society Reviews 2013, 42 (7), 2963-2985.

13. Hetsch, F.; Xu, X.; Wang, H.; Kershaw, S. V.; Rogach, A. L., Journal of Physical Chemistry Letters 2011, 2 (15), 1879-1887.

14. Pelcher, K. E.; Milleville, C. C.; Wangoh, L.; Chauhan, S.; Crawley, M. R.; Marley, P. M.; Piper, L. F. J.; Watson, D. F.; Banerjee, S., Chemistry of Materials 2015, 27 (7), 2468-2479.

15. Marley, P. M.; Stabile, A. A.; Kwan, C. P.; Singh, S.; Zhang, P.; Sambandamurthy, G.; Banerjee, S., Advanced Functional Materials 2013, 23 (2), 153-160. 
16. Ghorbani-Asl, M.; Enyashin, A. N.; Kuc, A.; Seifert, G.; Heine, T., Physical Review B: Condensed Matter and Materials Physics 2013, 88 (24), 245440/1-245440/7.

17. Pujari, B. S.; Kanhere, D. G., Journal of Physical Chemistry C 2009, 113 (50), 21063-21067.

18. Wangoh, L.; Marley, P. M.; Quackenbush, N. F.; Sallis, S.; Fischer, D. A.; Woicik, J. C.; Banerjee, S.; Piper, L. F. J., Applied Physics Letters 2014, Ahead of Print.

19. Marley, P. M.; Horrocks, G. a.; Pelcher, K. E.; Banerjee, S., Chem. Commun. 2015, 51, 5181-5198.

20. Beard, M. C.; Luther, J. M.; Nozik, A. J., Nature Nanotechnology 2014, 9 (12), 951-954.

21. Grigioni, I.; Stamplecoskie, K. G.; Selli, E.; Kamat, P. V., Journal of Physical Chemistry C 2015, 119 (36), 20792-20800.

22. Luque, A.; Marti, A.; Stanley, C., Nature Photonics 2012, 6 (3), 146-152.

23. Kim, J.-P.; Christians, J. A.; Choi, H.; Krishnamurthy, S.; Kamat, P. V., Journal of Physical Chemistry Letters 2014, 5 (7), 1103-1109.

24. Marley, P. M.; Abtew, T. A.; Farley, K. E.; Horrocks, G. A.; Dennis, R. V.; Zhang, P.; Banerjee, S., Chemical Science 2015, 6, 1712-1718.

25. Watson, D. F., Journal of Physical Chemistry Letters 2010, 1 (15), 2299-2309.

26. Vogel, R.; Hoyer, P.; Weller, H., Journal of Physical Chemistry 1994, 98 (12), 3183-8.

27. Lee, H. J.; Wang, M.; Chen, P.; Gamelin, D. R.; Zakeeruddin, S. M.; Gratzel, M.; Nazeeruddin, M. K., Nano Letters 2009, 9 (12), 4221-4227.

28. Pathan, H. M.; Lokhande, C. D., Bulletin of Materials Science 2004, 27 (2), 85-111.

29. Zhang, H.; Cheng, K.; Hou, Y. M.; Fang, Z.; Pan, Z. X.; Wu, W. J.; Hua, J. L.; Zhong, X. H., Chemical Communications (Cambridge, United Kingdom) 2012, 48 (91), 11235-11237.

30. Pan, Z.; Mora-Sero, I.; Shen, Q.; Zhang, H.; Li, Y.; Zhao, K.; Wang, J.; Zhong, X.; Bisquert, J., Journal of the American Chemical Society 2014, 136 (25), 9203-9210.

31. Horrocks, G. A.; Likely, M. F.; Velazquez, J. M.; Banerjee, S., Journal of Materials Chemistry A: Materials for Energy and Sustainability 2013, 1 (48), 15265-15277.

32. Nevins, J. S.; Coughlin, K. M.; Watson, D. F., ACS Applied Materials \& Interfaces 2011, 3 (11), $4242-4253$.

33. Stenzel, O., Springer: 2005.

34. Mane, A. A.; Ganbavle, V. V.; Gaikwad, M. A.; Nikam, S. S.; Rajpure, K. Y.; Moholkar, A. V., Journal of Analytical and Applied Pyrolysis 2015, 115, 57-65.

35. Burstein, E., Physical Review 1954, 93, 632-3.

36. O'Regan, B.; Graetzel, M.; Fitzmaurice, D., Journal of Physical Chemistry 1991, 95 (26), 10525-8.

37. O'Regan, B.; Graetzel, M.; Fitzmaurice, D., Chemical Physics Letters 1991, 183 (1-2), 89-93.

38. Rothenberger, G.; Fitzmaurice, D.; Graetzel, M., Journal of Physical Chemistry 1992, 96 (14), 5983-6.

39. Redmond, G.; Fitzmaurice, D.; Graetzel, M., Journal of Physical Chemistry 1993, 97 (27), 6951-4. 40. Othonos, A.; Christofides, C.; Zervos, M., Applied Physics Letters 2013, 103 (13), 133112/1$133112 / 4$.

41. Maganas, D.; Roemelt, M.; Haevecker, M.; Trunschke, A.; Knop-Gericke, A.; Schloegl, R.; Neese, F., Physical Chemistry Chemical Physics 2013, 15 (19), 7260-7276.

42. Velazquez, J. M.; Jaye, C.; Fischer, D. A.; Banerjee, S., Journal of Physical Chemistry C 2009, 113 (18), 7639-7645.

43. Bawendi, M. G.; Wilson, W. L.; Rothberg, L.; Carroll, P. J.; Jedju, T. M.; Steigerwald, M. L.; Brus, L. E., Physical Review Letters 1990, 65 (13), 1623-6.

44. Logunov, S.; Green, T.; Marguet, S.; El-Sayed, M. A., Journal of Physical Chemistry A 1998, 102 (28), 5652-5658.

45. Burda, C.; Green, T. C.; Link, S.; El-Sayed, M. A., Journal of Physical Chemistry B 1999, 103 (11), 1783-1788. 
46. Radich, J. G.; Peeples, N. R.; Santra, P. K.; Kamat, P. V., Journal of Physical Chemistry C 2014, 118 (30), 16463-16471.

47. Dibbell, R. S.; Watson, D. F., Journal of Physical Chemistry C 2009, 113 (8), 3139-3149. 